\title{
Increased whiB7 expression and antibiotic resistance in Mycobacterium chelonae carrying two prophages
}

\author{
Jaycee Cushman ${ }^{1}$, Emma Freeman ${ }^{1,2}$, Sarah McCallister ${ }^{1}$, Anna Schumann ${ }^{1}$, Keith W. Hutchison ${ }^{1,2}$ and \\ Sally D. Molloy ${ }^{1,2^{*}}$
}

\begin{abstract}
Background: The global rise in the incidence of non-tuberculosis mycobacterial infections is of increasing concern due their high levels of intrinsic antibiotic resistance. Although integrated viral genomes, called prophage, are linked to increased antibiotic resistance in some bacterial species, we know little of their role in mycobacterial drug resistance.

Results: We present here for the first time, evidence of increased antibiotic resistance and expression of intrinsic antibiotic resistance genes in a strain of Mycobacterium chelonae carrying prophage. Strains carrying the prophage McProf demonstrated increased resistance to amikacin. Resistance in these strains was further enhanced by exposure to sub-inhibitory concentrations of the antibiotic, acivicin, or by the presence of a second prophage, BPs. Increased expression of the virulence gene, whiB7, was observed in strains carrying both prophages, BPs and McProf, relative to strains carrying a single prophage or no prophages.

Conclusions: This study provides evidence that prophage alter expression of important mycobacterial intrinsic antibiotic resistance genes and additionally offers insight into the role prophage may play in mycobacterial adaptation to stress.
\end{abstract}

Keywords: Prophage, Antibiotic resistance, Mycobacteria, whiB7, Polymorphic toxin

\section{Background}

Prophage (integrated viral genomes) are major drivers of bacterial virulence and antibiotic resistance in bacteria, yet the mechanisms of prophage-mediated antibiotic resistance are unknown $[1,2] \cdot$ Prophages are common in mycobacteria, including clinical isolates of emerging non-tuberculosis pathogenic mycobacteria, Mycobacterium avium and $M$. abscessus [3, 4]. M. abscessus is of significant concern as it is considered one of the most antibiotic resistant pathogens $[5,6]$. Extensively resistant

\footnotetext{
* Correspondence: sally.dixon@maine.edu

'Department of Molecular and Biomedical Sciences, University of Maine, Orono, ME, United States

${ }^{2}$ The Honors College, University of Maine, Orono, ME, United States
}

isolates share increased expression of conserved mycobacterial intrinsic antibiotic resistance genes such as whiB7, making drug treatment challenging [5-7]. Understanding how intrinsic antibiotic resistance genes are regulated in pathogenic mycobacteria would provide opportunities to develop novel and more effective treatment approaches [7, 8].

Clarithromycin (CLA) combined with amikacin (AMK) is the treatment of choice for M. abscessus infections but with the emergence of resistance to both of these drugs, treatment is becoming increasingly difficult $[7,9]$. Recent efforts in sequencing of clinical M. abscessus isolates determined that mutations in the 23S rRNA gene, $r r l$, and in the erm gene, which confers macrolide

C C The Author(s). 2021 Open Access This article is licensed under a Creative Commons Attribution 4.0 International License, which permits use, sharing, adaptation, distribution and reproduction in any medium or format, as long as you give appropriate credit to the original author(s) and the source, provide a link to the Creative Commons licence, and indicate if changes were made. The images or other third party material in this article are included in the article's Creative Commons licence, unless indicated otherwise in a credit line to the material. If material is not included in the article's Creative Commons licence and your intended use is not permitted by statutory regulation or exceeds the permitted use, you will need to obtain permission directly from the copyright holder. To view a copy of this licence, visit http://creativecommons.org/licenses/by/4.0/. The Creative Commons Public Domain Dedication waiver (http://creativecommons.org/publicdomain/zero/1.0/) applies to the data made available in this article, unless otherwise stated in a credit line to the data. 
(e.g. clarithromycin) resistance, are typically associated with elevated CLA resistant phenotypes but did not account for all the clarithromycin resistant phenotypes [7]. What was consistent in all clarithromycin-resistant isolates was elevated expression of genes in the whiB7 regulon, including the transcription factor whiB7 and its target genes, the drug efflux pumps plus other antibiotic resistance genes including erm and eis [7, 10-12]. These latter genes confer macrolide and aminoglycoside resistance, respectively. Likewise, in AMK-resistant isolates of $M$. abscessus there is typically a 10 -fold increase in whiB7 expression relative to AMK susceptible strains [13]. whiB7 is conserved across all mycobacteria, including pathogenic and non-pathogenic species such as $M$. tuberculosis, M. abscessus, $M$. chelonae and M. smegmatis $[14,15]$. Characterizing the pathways that lead to increased whiB7 expression and intrinsic drug resistance in pathogenic mycobacteria will be important for identifying new targets for novel drug development $[9,16,17]$.

The majority of bacterial pathogens carry prophage that are known to contribute to bacterial virulence and fitness $[2,18,19]$. Prophage introduce novel genes into bacterial genomes that can result in phenotypes that are more competitive in bacterial populations $[2,18]$. Prophage also contribute to antibiotic resistance and persistence. Nine cryptic prophages (transcriptionally active prophage that cannot carry out lytic infections) in E. coli significantly increase resistance to quinolones and betalactam antibiotics compared to strains in which all or combinations of prophages had been cured, although the mechanism by which these prophage affected resistance was not reported [1]. Toxin/antitoxin (TA) systems encoded by prophage are also known to increase resistance and persistence in the presence of antibiotics. In $E$. coli, prophage-encoded TA pair RalR/RalA increases resistance to broad-spectrum fosfomycin and the RelE toxin of prophage Qin leads to persistence in the presence of ciprofloxacin, ampicillin and tobramycin [2022]. The majority of mycobacterial pathogens also carry prophage and they are hypothesized to play a role in virulence, yet remain largely uninvestigated $[3,23,24]$.

In this study we examine the impact of two mycobacteriophages on intrinsic antibiotic resistance and whiB7 expression in the non-tuberculosis mycobacterial pathogen, $M$. chelonae, a member of the $M$. abscessus/chelonae complex. The disease caused by $M$. chelonae, mainly soft tissue and disseminating infections, differs from that of $M$. abscessus; however, the whiB7-dependent mechanisms of intrinsic resistance are conserved across all mycobacteria, including $M$. chelonae $[15,25]$. We identified a naturally occurring prophage in $M$. chelonae that also occurs in the sequenced genomes of at least 25 clinical isolates of $M$. abscessus. We characterized the genome of the M. chelonae prophage, McProf, and created a cured strain that lacks prophage. Antibiotic resistance and gene expression of this strain was compared to that of $M$. chelonae carrying a single or multiple prophages.

\section{Results}

Double lysogens of $M$. chelonae have increased resistance to aminoglycosides amikacin and tobramycin

The wild type M. chelonae (ATCC 35752) carries a naturally occurring 67,657-bp prophage that we have named McProf. To determine how prophages impact gene expression and the antibiotic resistance phenotype of $M$. chelonae we added a second prophage. We identified three mycobacteriophages capable of infecting $M$. chelonae, Muddy, WildCat and BPs, of which only BPs is known to be temperate [26-28]. A double lysogen of $M$. chelonae was created from the WT M. chelonae strain using the cluster G mycobacteriophage, BPs [28]. BPs integrates into an attB site located within the 3' end of the host tRNA-Arg gene (BB28_RS01100), that is similar to the BPs attB site in M. smegmatis (Msmeg_6349) [28]. BPs lysogens of the M. chelonae WT strain (BPs, McProf) appear to be more stable than BPs lysogens of $M$. smegmatis. Lysogens form at a higher efficiency in M. chelonae WT (25\%) compared to that in M. smegmatis $(5 \%)$ and release fewer particles into cell culture supernatant $\left(10^{4}-10^{5}\right.$ PFUs $\mathrm{ml}^{-1}$ compared to $10^{10}$ PFUs $\left.\mathrm{ml}^{-1}\right)[28,29]$.

To determine if the presence of a second prophage in $M$. chelonae alters susceptibility to antibiotics, we determined the minimum inhibitory concentrations (MIC) for the double $M$. chelonae lysogen (BPs, McProf) relative to the WT strain (McProf) in the presence of varying levels of the aminoglycosides, amikacin (AMK) and tobramycin (TOB), and tetracycline (TET) (Table 1). The presence of the second prophage, BPs, significantly increased resistance to both aminoglycosides. There was not a consistent significant difference in resistance to TET. As a positive control, we exposed the $M$. chelonae (McProf) strain to sub-inhibitory concentrations of acivicin (ACI), a known inducer of intrinsic resistance in mycobacteria [12]. As expected, ACI significantly increased the resistance of $M$. chelonae (McProf) in both the AMK and TOB assays (Table 1). ACI treatment did not significantly alter TET resistance of $M$. chelonae (McProf).

We also determined the viability of the strains after antibiotic treatment by adding AlamarBlue to the wells to detect metabolic activity (Fig. 1). There was a statistically significant difference in viability between the double lysogen and WT strains treated with $64 \mu^{\mathrm{g} \mathrm{ml}} \mathrm{m}^{-1}$ AMK and $8 \mu \mathrm{g} \mathrm{ml}^{-1}$ TOB. We noted a slight increase in viability of the WT strain at $8 \mu \mathrm{g} \mathrm{ml}^{-1}$ TOB; however, there was no evidence of growth at this concentration of TOB. The WT strain treated with ACI in both the AMK 
Table 1 Minimum inhibitory concentrations of M. chelonae strains carrying one, two or no prophage in the presence and absence of $\mathrm{ACl}$ treatment

\begin{tabular}{|c|c|c|c|c|c|c|c|c|}
\hline \multirow{3}{*}{$\begin{array}{l}\text { Strain (prophage): } \\
\text { Antibiotic: } \\
\text { ACl treatment: }\end{array}$} & \multicolumn{8}{|c|}{$\mathrm{MIC}^{\mathrm{a}}\left(\mu \mathrm{g} \mathrm{m}^{-1}\right)$} \\
\hline & \multicolumn{2}{|l|}{ AMK } & \multicolumn{2}{|l|}{ TOB } & \multicolumn{2}{|l|}{ TET } & \multicolumn{2}{|l|}{ CLA } \\
\hline & $-\mathrm{ACl}$ & $+\mathrm{ACl}$ & $-\mathrm{ACl}$ & $\overline{+\mathrm{ACl}}$ & $-\mathrm{ACl}$ & $+\mathrm{ACl}$ & $-\mathrm{ACl}$ & $+\mathrm{ACl}$ \\
\hline WT (McProf) & 64 & 128 & 8 & 16 & 16 & 16 & 3 & 6 \\
\hline WT (McProf, BPs) & 128 & 128 & 16 & ND & 16 & 16 & 3 & ND \\
\hline$\triangle$ McProf & 32 & 64 & 8 & 8 & 16 & 16 & 3 & 6 \\
\hline$\triangle \mathrm{McProf}$ (BPs) & 32 & 64 & 8 & ND & 16 & 16 & 3 & ND \\
\hline
\end{tabular}

${ }^{\mathrm{a}} \mathrm{MIC}$ determined as the lowest drug concentration that completely inhibited growth

and TOB assay had the highest viability at these drug concentrations. Some background reduction of AlamarBlue was observed for both strains at doses higher than the observed MIC; however, there was no growth detected in those wells.

\section{Isolation of a non-lysogen and single BPs lysogen of $M$. chelonae}

To better understand how the presence of the second prophage increases antibiotic resistance, we generated a strain of $M$. chelonae that contains no prophage ( $M$. chelonae ( $\Delta \mathrm{McProf})$ ) and from that a single BPs lysogen of $M$. chelonae. To remove the McProf prophage we created a recombinant strain of $M$. chelonae (McProf) that overexpresses the McProf excise gene, gp5, from an inducible mycobacterial expression plasmid (Table 2) [30]. Using sets of PCR primers that amplify either the bacterial attachment site $(a t t B)$ and the phage attachment site $(a t t P)$ or the hybrid prophage attachment sites, $a t t L$ and $a t t R$, we identified ATc-induced bacterial colonies that had an intact $a t t B$ site, indicating that the McProf prophage had been lost and that McProf has an active integrase system (Table 3) (data not shown). To determine if McProf phage particles are released from $M$. chelonae (McProf) cells through spontaneous induction, concentrated culture supernatants were plated onto lawns of the newly acquired non-lysogen strain ( $\Delta$ McProf), but we were unable to detect plaques. PCR analysis of $M$. chelonae (McProf) culture supernatants also failed to detect the McProf attP sequence, which would have indicated the presence of either excised McProf genome or linear McProf genome in phage particles. It is possible that there is a mutation that we were not able to identify that prevents McProf from carrying out a successful lytic infection. Alternatively, M. chelonae may not be the natural host and McProf is capable of lytically infecting other mycobacterial hosts.

The non-lysogen strain of $M$. chelonae ( $\Delta \mathrm{McProf})$ was used to isolate single lysogens of BPs. Although we were able to isolate BPs lysogens in the non-lysogen strain of M. chelonae, they are less stable than BPs lysogens formed in the WT strain (McProf) and comparable to lysogens formed in M. smegmatis [28, 29]. Lysogens formed at an efficiency of $\sim 5 \%$, and the titer of BPs in lysogen culture supernatants was $10^{10}$ PFUs $\mathrm{ml}^{-1}$, several orders of magnitude higher than that of the double lysogen $\left(10^{5}\right.$ PFUs $\left.\mathrm{ml}^{-1}\right)$.

\section{Single and double lysogens carrying McProf have higher AMK resistance than strains that lack McProf}

To determine the roles of prophages BPs and McProf in the increased resistance observed in the double lysogen, we determined the MIC and viability of double (BPs, McProf) and single (BPs or McProf) M. chelonae lysogens relative to non-lysogen cells ( $\triangle \mathrm{McProf}$ ) in the presence of varying levels of AMK, TOB, TET and CLA (Table 1, Fig. 2). The presence of the naturally occurring prophage, McProf, significantly contributes to AMK resistance in $M$. chelonae in the presence and absence of ACI treatment (Table 1). The WT strain carrying McProf alone had a higher MIC for AMK $\left(64 \mu \mathrm{g} \mathrm{mL}^{-1}\right)$ relative to the non-lysogen strain ( $\triangle \mathrm{McProf}$ ) (MIC of $32 \mu \mathrm{g} \mathrm{mL}^{-1)}[10,12]$. Treatment of these two strains with ACI increased the MIC for both strains; however, the MIC for ACI-treated WT (McProf) strain was two-fold higher than that of the ACI-treated non-lysogen ( $\triangle$ McProf) strain (Table 1.) The presence of a second prophage, BPs, also increases resistance to AMK, with bacterial growth at doses as high as $64 \mu \mathrm{g} \mathrm{mL}^{-1}$. Although the double lysogen had the same MIC as the ACI-treated WT strain $\left(128 \mu \mathrm{g} \mathrm{mL}^{-1}\right)$ (Table 1$)$, the cell viability of the ACI-treated WT strain was statistically higher than that of the double lysogen (Fig. 2a). BPs alone had no effect on AMK resistance suggesting that BPs only increases AMK resistance through an interaction with the naturally occurring prophage, McProf.

The presence of the prophages McProf and BPs also altered TOB resistance in $M$. chelonae (Table 1 and Fig. 2b). The WT (McProf) strain did not have a higher TOB MIC than the non-lysogen strain $\left(8 \mu \mathrm{g} \mathrm{mL}^{-1}\right)$, but in the presence of $\mathrm{ACI}$, the MIC for WT (McProf) strain increased two-fold $\left(16 \mu \mathrm{g} \mathrm{mL}^{-1}\right)$, whereas the MIC for the 


\section{a}
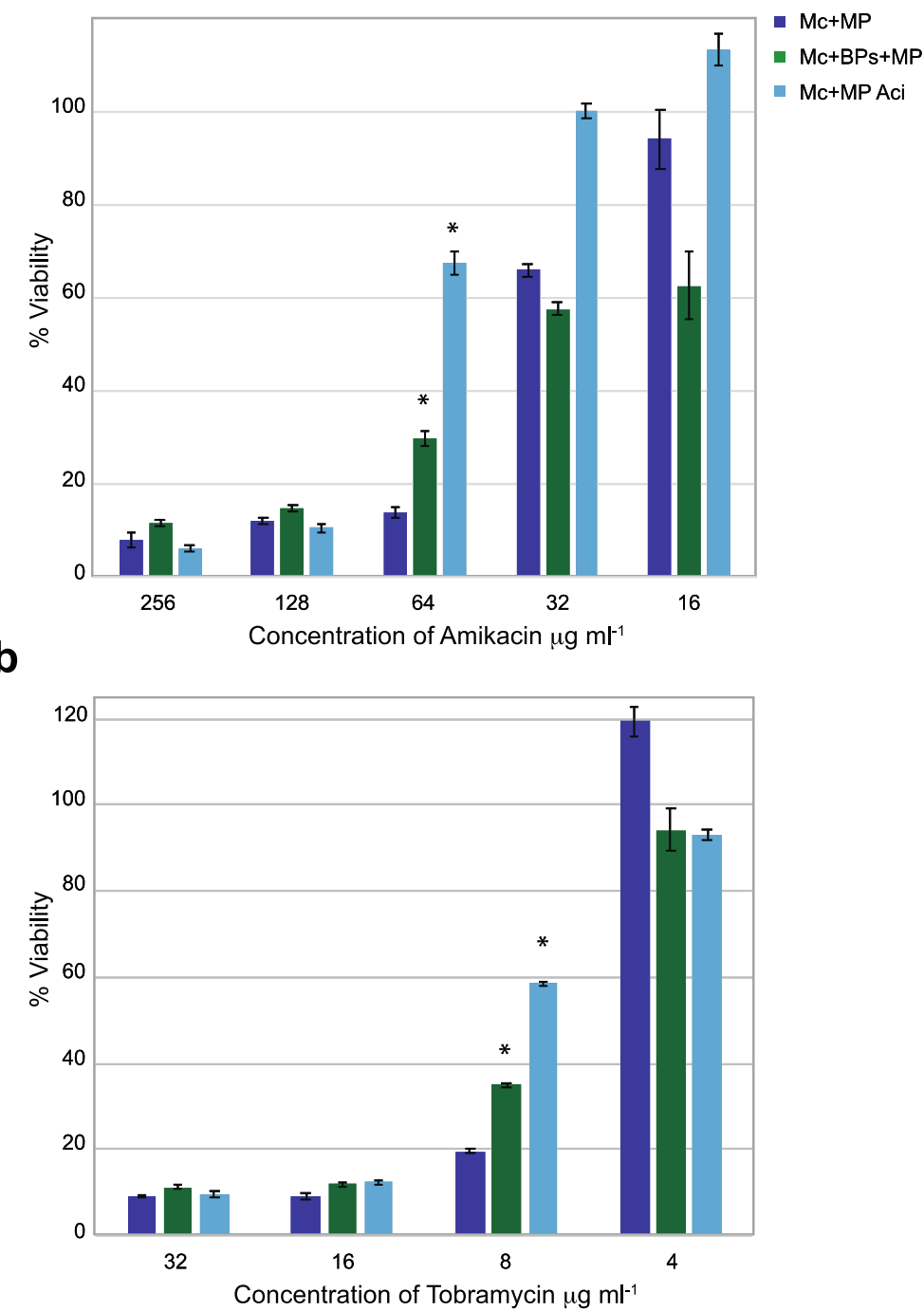

Fig. 1 Percent viability of M. chelonae carrying single prophage McProf (MP) and two prophages BPs and McProf in the presence of varying concentrations of a. AMK and b. TOB. As a positive control, single McProf lysogens were treated with $75 \mu \mathrm{M}$ acivicin (Aci), a known inducer of whiB7. Graphs represent average values \pm SE of the mean with $n=6$. The optical density was measured at $570-$ and $600 \mathrm{~nm}$ after addition of $1 \mu \mathrm{l}$ of AlamarBlue and the percent difference in reduction between antibiotic-treated cells and untreated cells was calculated. Mean percent reduction by $M$. chelonae that are statistically significant are indicated by an Asterix (Wilcoxon rank sum, $p<0.05$ ). Data is representative of three independent experiments

Table 2 Bacterial strains and plasmids used in this study

\begin{tabular}{lll}
\hline Strains & Strain Description & Source \\
\hline Escherichia coli & & Supercompetent cells \\
DH5a & Laboratory strain of M. chelonae ATCC 35752 with naturally-occurring prophage, McProf \\
M. chelonae WT & M. chelonae +McProf +BPs & NEB \\
$\begin{array}{ll}\text { M. chelonae double lysogen } \\
\text { M. chelonae nonlysogen }\end{array}$ & M. chelonae $\Delta$ McProf & This study \\
M. chelonae BPs single lysogen & M. chelonae $\Delta$ McProf+BPs & This study \\
\hline
\end{tabular}


Table 3 PCR primers used in this study

\begin{tabular}{|c|c|c|c|c|c|}
\hline Description & Primers & Sequence (5' to $\left.3^{\prime}\right)$ & $\begin{array}{l}\mathrm{Tm} \\
\left({ }^{\circ} \mathrm{C}\right)\end{array}$ & $\begin{array}{l}\% \\
\text { GC }\end{array}$ & $\begin{array}{l}\text { amplicon size } \\
\text { (bp) }\end{array}$ \\
\hline \multirow{4}{*}{$\begin{array}{l}\text { Primers used to detect McProf phage attachment sites in } M \text {. } \\
\text { chelonae }\end{array}$} & Mc_attL_F & CGTCACGTTGGGGACTATCT & 56.5 & 55 & 212 \\
\hline & Mc_attL_R & TTGAGCTGCGGATAACCTCT & 56 & 50 & \\
\hline & Mc_attR_F & CGCTTGTAATCGTCGTCGTA & 54.7 & 50 & 1067 \\
\hline & McProphageRR & ATAACTTTCGGCGGTTCCTT & 54.5 & 45 & \\
\hline \multirow{4}{*}{$\begin{array}{l}\text { Primers used to detect BPs phage attachment sites in } M \text {. } \\
\text { chelonae }\end{array}$} & BPs_attP_L & GCTTTATCCAGGGTTGACCA & 54.8 & 50 & 203 \\
\hline & BPs_attP_R & GTTCCGATTAGTTGGCTGGA & 54.8 & 50 & \\
\hline & BPs_attB_L & GTCTCGTTACTGGCGAGCTT & 57.1 & 55 & 548 \\
\hline & BPs_attB_R & CGGGTAGTAGGCAGATGAGC & 57.2 & 60 & \\
\hline
\end{tabular}

\section{a}

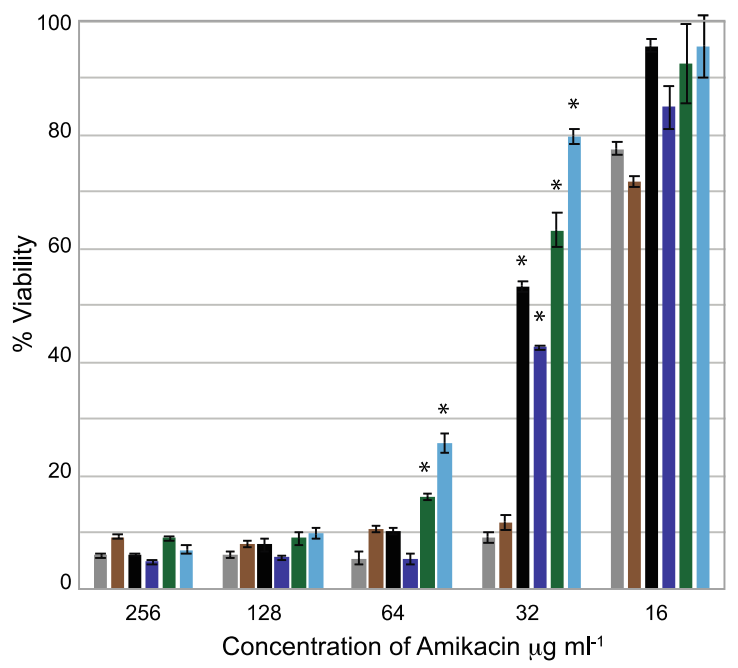

b

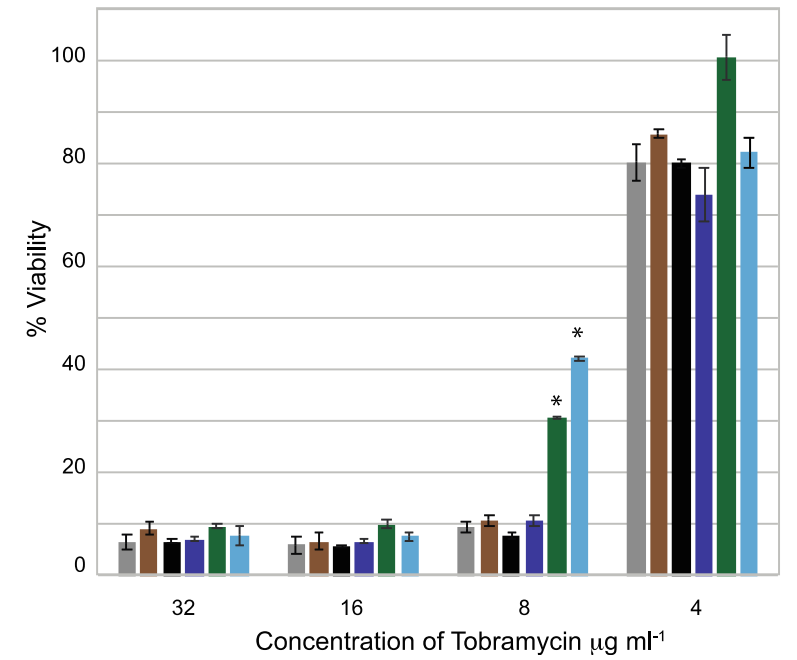

Fig. 2 Percent viability of M. chelonae carrying single prophage McProf, two prophages BPs and McProf, no prophage, or single BPs prophage in the presence of varying concentrations of $\mathbf{a}$. AMK and $\mathbf{b}$. TOB. As a positive control, single McProf lysogens and non-lysogen cultures were treated with $75 \mu \mathrm{M}$ acivicin (Aci), a known inducer of whiB7. Graphs represent average values \pm SE of the mean with $n=6$. The optical density of was measured at 570- and $600 \mathrm{~nm}$ after addition of $1 \mu \mathrm{l}$ of AlamarBlue and the percent difference in reduction between antibiotic-treated cells and untreated cells was calculated. Mean percent reduction by M. chelonae that are statistically significant are indicated by an Asterix (Wilcoxon rank sum, $p<0.05)$. Data is representative of three independent experiments 
non-lysogen ( $\Delta \mathrm{McProf})$ strain remained $8 \mu \mathrm{g} \mathrm{mL} L^{-1}$. It is possible a difference would be detected at TOB doses between 4- and $8 \mu \mathrm{g} \mathrm{mL}^{-1}$. The TOB MIC for the double lysogen (BPs, McProf) was the same as that for the ACI-treated WT (McProf) strain; however the viability for ACI-treated WT (McProf) strain was significantly higher than that of the double lysogen at $8 \mu \mathrm{g} \mathrm{mL}^{-1}$ (Table 1 and Fig. 2b).

The presence of prophages had little effect on TET and CLA resistance in M. chelonae (Table 1). ACI treatment induced significant increases in CLA resistance but not TET resistance in the WT (McProf) and nonlysogen ( $\Delta$ McProf) strains.

\section{Prophage McProf enhances AMK resistance in response to sub-inhibitory concentrations of antibiotics}

Because the M. chelonae (McProf) strain treated with ACI had higher AMK resistance than the non-lysogen strain treated with $\mathrm{ACI}$, we wondered if the presence of prophage McProf enhances the effect of sub-inhibitory concentrations of antibiotics on AMK resistance. To determine the interaction between ACI and the presence of one or both prophages, we treated all four lysogen and non-lysogen strains with sub-inhibitory concentrations of $\mathrm{ACI}$ and repeated the AMK resistance assay. The presence of McProf increases the effect of ACI on AMK resistance compared to the non-lysogen whereas the BPs prophage alone does not (Table 1 and Fig. 3). The double lysogen treated with ACI did not have a higher MIC than the WT (McProf) strain treated with
ACI; however, cultures of the ACI-treated double lysogen (BPs, McProf) did consistently have a statistically higher viability than that of ACI-treated WT (McProf) strain at AMK doses of $64 \mu \mathrm{g} \mathrm{mL}^{-1}$. The presence of BPs and ACI appear to interact with McProf to increase AMK resistance.

\section{The whiB7 regulon is upregulated in double lysogens of M. chelonae}

RNAseq analysis was performed on RNA isolated from the WT (McProf) and double lysogen (BPs, McProf) $M$. chelonae strains to learn if the presence of the second prophage, BPs, impacted expression of genes that may be involved in mycobacterial antibiotic resistance. The presence of prophage BPs significantly altered expression of $M$. chelonae genes, including numerous putative virulence genes. Out of 4867 genes in the $M$. chelonae genome, $417(8.5 \%)$ were differentially regulated in the double lysogen.

(BPs, McProf) (Fig. 4).

The majority of the top-ranked genes in the double lysogen belonged to the whiB 7 regulon, genes in $M$. tuberculosis with functions related to antibiotic resistance and increased survival in macrophage (Tables 4 and 5) [15]. The transcription factor, identified as whiB7 (BB28_ RS17590), was the fifth most highly upregulated gene in the double lysogen with a fold change of 26.5 ( $\log 2 \mathrm{FC}=$ $\left.4.7, \mathrm{FDR}=1.3^{-73}\right) \quad($ Table 4$)$. The WhiB7 peptide sequence shares $95 \%$ identity with the M. abscessus WhiB7 peptide (MAB_3508c) and has all the conserved residues

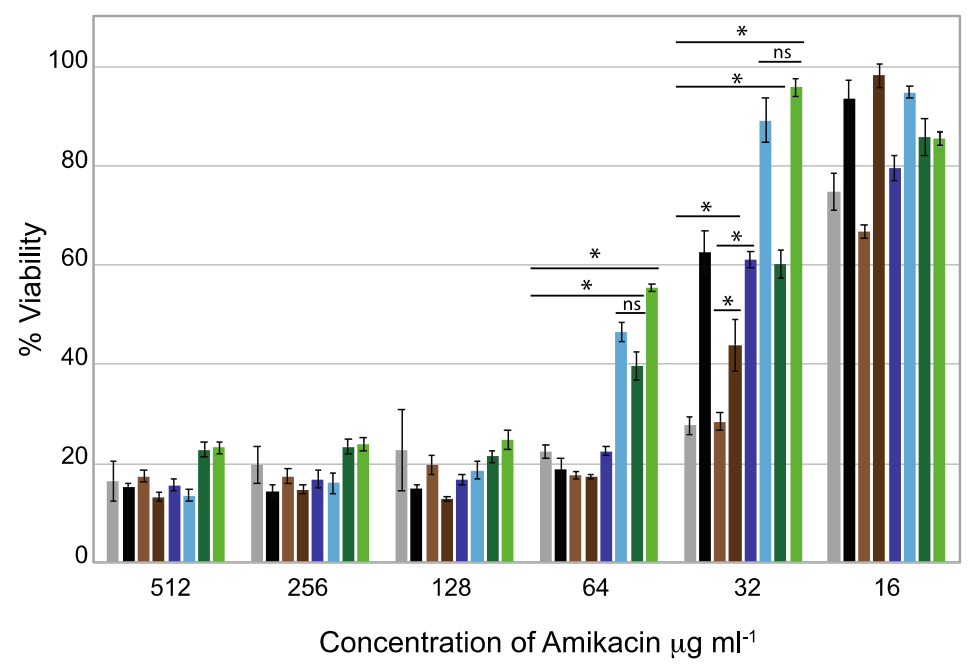

- Mc $\Delta \mathrm{MP}$

- Mc $\triangle M P A c i$

- Mc $\triangle M P+B P s$

- Mc $\Delta \mathrm{MP}+\mathrm{BP} s \mathrm{Aci}$

- Mc+MP

- Mc+MP Aci

- $\mathrm{Mc}+\mathrm{BPs}+\mathrm{MP}$

- Mc+BPs+MP Aci both prophages BPs and McProf (Mc + BPs + MP) in the presence of varying concentrations of amikacin. To determine if the presence of each prophage interacts with sub-inhibitory concentrations of antibiotics, each strain was treated or not treated with $75 \mu \mathrm{M}$ acivicin (ACI). Graphs represent average values \pm SE of the mean with $n=3$. The optical density of was measured at 570 - and $600 \mathrm{~nm}$ after the addition of $2 \mu \mathrm{l}$ of AlamarBlue and the percent difference in reduction between antibiotic-treated cells and untreated cells was calculated. Data is representative of two independent experiments 


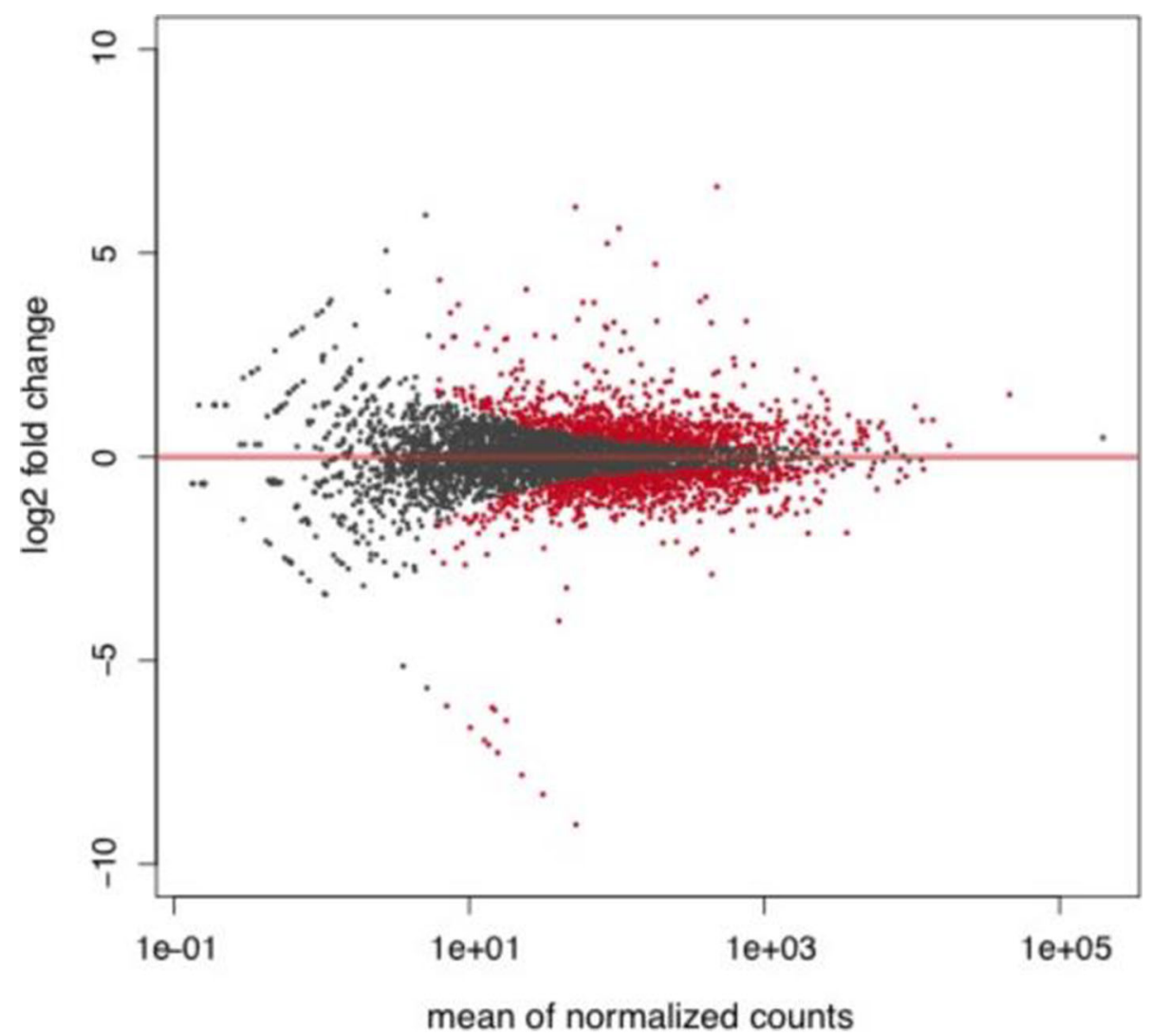

Fig. 4 MA Plot presenting the relationship between average expression level (mean of normalized counts) of $M$. chelonae genes and their fold change (log2fold change) in the double M. chelonae lysogen (BPs, McProf) relative to the WT strain (McProf). Red indicates genes identified as differentially expressed at an FDR of 0.05 or smaller

that form the iron sulfur cluster binding domain. It also has the glycine-rich motif of the signature WhiB7 Cterminal "A/T Hook" DNA binding domain, which binds to AT-rich sequences adjacent to target gene promoters $[11,12]$. The $M$. chelonae genome contains a large whiB7 regulon like that of $M$. abscessus, with 103 of the 128 whiB7 regulon genes found in M. abscessus [12]. We identified a total of 30 upregulated genes that belong to the whiB7 regulon, many of which are known to contribute to drug resistance such as GNAT acetyltransferases, eis1 (BB28_RS05390) and eis2 (BB28_RS22650), multidrug efflux transporter tap (BB28_RS06750), and the tetV efflux pump (BB28_RS13560). Also included in this regulon are additional GNAT acetyltransferases (BB28_ RS23100 and BB28_RS01940) and ABC transporters with ATP binding domains that likely function in drug resistance (Tables 4 and 5). In $M$. abscessus and $M$. tuberculosis, erm is part of the whiB7 regulon and provides macrolide resistance but the gene is not present in the $M$. chelonae genome [31]. M. chelonae lacks this whi $\mathrm{B} 7$ regulon gene, but it does encode a newly discovered gene in the whiB7 regulon, the ribosome splitting factor $h f l X$ (MAB_3042c), which is reported to contribute to macrolide resistance in $M$. abscessus [31, 32]. Expression of the $M$. chelonae $h f l X$ was slightly elevated in double lysogens relative to the WT strain (McProf) (BB28 RS14985; $\log 2 \mathrm{FC}=1.5, \mathrm{FDR}=8.4^{-33}$ ) but this did not result in significant changes in CLA resistance in the double lysogen (Table 5). An additional 25 whiB7 regulon genes were upregulated but had fold changes of less than 2 .

The most highly regulated gene, with a 99-fold increase in expression, was annotated as a flotillin protein with no known function (BB28_RS01845) $(\log 2 \mathrm{FC}=6.6$, $\mathrm{FDR}=6.4^{-124}$ ) (Table 4). Several of the most down regulated genes in the lysogen include a padR-family transcription factor (BB28_RS01835, $\log 2 \mathrm{FC}=-8.3, \mathrm{FDR}=$ $\left.1.4^{-10}\right)$ and genes involved in glycerol uptake $(g l p \mathrm{~F}$, BB28_RS01835, $\log 2 \mathrm{FC}=-6.2, \mathrm{FDR}=4.5^{-06}$ ) and metabolism $\left(g l p \mathrm{~K}, \mathrm{BB} 28 \_\mathrm{RS} 01840, \log 2 \mathrm{FC}=-9.0, \mathrm{FDR}=\right.$ $1.1^{-12}$ ) (Table 4) [33].

\section{Upregulation of whiB7 only occurs in double lysogens of M. chelonae}

To determine how the presence and absence of each prophage impacts whiB7 expression, whiB7 mRNA levels were measured by qPCR in the BPs single lysogen, double 
Table 4 Top 20 upregulated and downregulated M. chelonae genes in the double lysogen (BPs, McProf) relative to WT M. chelonae (McProf)

\begin{tabular}{|c|c|c|c|c|c|c|c|}
\hline $\begin{array}{l}\mathrm{MCH}^{\mathrm{a}} \\
\text { gene ID }\end{array}$ & Predicted function $^{b}$ & $\log 2 \mathrm{FC}^{\mathrm{c}}$ & FDR $^{d}$ & $\begin{array}{l}\text { MAB }^{\mathrm{e}} \\
\text { Gene ID }\end{array}$ & MAB Gene Description & $\begin{array}{l}\text { MTB }^{f} \\
\text { Gene } \\
\text { ID }\end{array}$ & MTB Gene Description \\
\hline $\begin{array}{l}\text { BB28_- } \\
\text { RS04255 }\end{array}$ & flotillin protein & 6.6 & $\begin{array}{l}6.4 \mathrm{E}- \\
124\end{array}$ & NA & NA & NA & NA \\
\hline $\begin{array}{l}\text { BB28_- } \\
\text { RS19005 }\end{array}$ & hypothetical protein & 6.1 & $\begin{array}{l}9.1 \mathrm{E}- \\
18\end{array}$ & $\begin{array}{l}\text { MAB } \\
3786 c\end{array}$ & Hypothetical protein & NA & NA \\
\hline $\begin{array}{l}\text { BB28 } \\
\text { RS23100 }\end{array}$ & $\mathrm{N}$-acetyltransferase & 5.6 & $\begin{array}{l}4.4 \mathrm{E}- \\
38\end{array}$ & $\begin{array}{l}\mathrm{MAB}_{-} \\
4621 \mathrm{C}\end{array}$ & Putative acetyltransferase & NA & NA \\
\hline $\begin{array}{l}\text { BB28 } \\
\text { RS23095 }\end{array}$ & hypothetical protein & 5.3 & $\begin{array}{l}2.8 \mathrm{E}- \\
35\end{array}$ & $\begin{array}{l}\text { MAB } \\
4620 \mathrm{C}\end{array}$ & Hypothetical protein & NA & NA \\
\hline $\begin{array}{l}\text { BB28 } \\
\text { RS17590 }\end{array}$ & $\begin{array}{l}\text { WhiB7 transcriptional } \\
\text { regulator }\end{array}$ & 4.7 & $\begin{array}{l}1.3 \mathrm{E}- \\
73\end{array}$ & $\begin{array}{l}\mathrm{MAB}_{-} \\
3508 \mathrm{C}\end{array}$ & $\begin{array}{l}\text { Putative transcriptional } \\
\text { regulator }\end{array}$ & Rv3197A & transcriptional regulator WhiB7 \\
\hline $\begin{array}{l}\text { BB28 } \\
\text { RS05390 }\end{array}$ & $\begin{array}{l}\text { GNAT family N- } \\
\text { acetyltransferase (eis } 1 \text { ) }\end{array}$ & 4.1 & $\begin{array}{l}5.8 \mathrm{E}- \\
12\end{array}$ & $\begin{array}{l}\mathrm{MAB}_{-} \\
1125 \mathrm{C}\end{array}$ & $\begin{array}{l}\text { Hypothetical acetyltransferase, } \\
\text { GNAT family }\end{array}$ & Rv1947 & hypothetical protein \\
\hline $\begin{array}{l}\text { BB28- } \\
\text { RS04260 }\end{array}$ & $\begin{array}{l}\text { class I SAM-dependent } \\
\text { methyltransferase }\end{array}$ & 3.9 & $\begin{array}{l}1.0 \mathrm{E}- \\
120\end{array}$ & $\begin{array}{l}\mathrm{MAB}_{-} \\
0963 \mathrm{C}\end{array}$ & $\begin{array}{l}\text { Putative polyketide synthase } \\
\text { protein }\end{array}$ & NA & NA \\
\hline $\begin{array}{l}\text { BB28_- } \\
\text { RS03915 }\end{array}$ & hypothetical protein & 3.8 & $\begin{array}{l}2.8 \mathrm{E}- \\
116\end{array}$ & $\begin{array}{l}\mathrm{MAB}_{-} \\
0857\end{array}$ & Putative monooxygenase & NA & NA \\
\hline $\begin{array}{l}\text { BB28 } \\
\text { RS20465 }\end{array}$ & KR domain-containing protein & 3.8 & $\begin{array}{l}3.4 \mathrm{E}- \\
26\end{array}$ & $\begin{array}{l}\mathrm{MAB}_{-} \\
4053 \mathrm{C}\end{array}$ & $\begin{array}{l}\text { Putative short chain } \\
\text { dehydrogenase/reductase }\end{array}$ & NA & NA \\
\hline $\begin{array}{l}\text { BB28_ } \\
\text { RS16665 }\end{array}$ & iron $A B C$ transporter permease & 3.8 & $\begin{array}{l}4.5 \mathrm{E}- \\
31\end{array}$ & $\begin{array}{l}\mathrm{MAB}_{-} \\
2262 \mathrm{C}\end{array}$ & $\begin{array}{l}\text { Hypothetical ABC transporter } \\
\text { ATP-binding protein }\end{array}$ & $\operatorname{Rv} 1348$ & $\begin{array}{l}\text { iron } A B C \text { transporter ATP- } \\
\text { binding protein/permease IrtA }\end{array}$ \\
\hline $\begin{array}{l}\text { BB28 } \\
\text { RS06460 }\end{array}$ & $\begin{array}{l}\text { NAD(P)-dependent } \\
\text { oxidoreductase }\end{array}$ & 3.4 & $\begin{array}{l}1.2 \mathrm{E}- \\
21\end{array}$ & $\begin{array}{l}\mathrm{MAB}_{-} \\
1344 \mathrm{C}\end{array}$ & $\begin{array}{l}\text { Putative DTDP-glucose-4,6- } \\
\text { dehydratase-related protein }\end{array}$ & Rv3468c & dTDP-glucose 4,6-dehydratase \\
\hline $\begin{array}{l}\text { BB28 } \\
\text { RS11540 }\end{array}$ & $\begin{array}{l}\text { ABC transporter ATP-binding } \\
\text { protein }\end{array}$ & 3.3 & $\begin{array}{l}3.5 \mathrm{E}- \\
64\end{array}$ & $\begin{array}{l}\mathrm{MAB}_{-} \\
2355 \mathrm{C}\end{array}$ & $\begin{array}{l}\text { Putative ABC transporter ATP- } \\
\text { binding protein }\end{array}$ & NA & NA \\
\hline $\begin{array}{l}\text { BB28 } \\
\text { RS22650 }\end{array}$ & $\begin{array}{l}\text { GNAT family N- } \\
\text { acetyltransferase (eis2) }\end{array}$ & 3.3 & $\begin{array}{l}1.4 \mathrm{E}- \\
176\end{array}$ & $\begin{array}{l}\mathrm{MAB}_{-} \\
4532 \mathrm{C}\end{array}$ & hypothetical protein & NA & NA \\
\hline $\begin{array}{l}\text { BB28 } \\
\text { RS06750 }\end{array}$ & $\begin{array}{l}\text { tap multidrug efflux } \\
\text { transporter }\end{array}$ & 3.3 & $\begin{array}{l}7.3 \mathrm{E}- \\
35\end{array}$ & $\begin{array}{l}\mathrm{MAB}_{-} \\
1409 \mathrm{C}\end{array}$ & $\begin{array}{l}\text { Putative drug antiporter } \\
\text { protein precursor }\end{array}$ & Rv1258c & multidrug-efflux transporter \\
\hline $\begin{array}{l}\text { BB28 } \\
\text { RS13560 }\end{array}$ & TetV Efflux Pump & 3.3 & $\begin{array}{l}9.8 \mathrm{E}- \\
94\end{array}$ & $\begin{array}{l}\mathrm{MAB}_{-} \\
2780 \mathrm{C}\end{array}$ & Putative transporter & NA & NA \\
\hline $\begin{array}{l}\text { BB28 } \\
\text { RS20470 }\end{array}$ & $\begin{array}{l}\text { pyridoxamine } 5 \text { '-phosphate } \\
\text { oxidase family protein }\end{array}$ & 3.2 & $\begin{array}{l}4.1 \mathrm{E}- \\
29\end{array}$ & $\begin{array}{l}\mathrm{MAB}_{-} \\
4054 \mathrm{C}\end{array}$ & hypothetical protein & NA & NA \\
\hline $\begin{array}{l}\text { BB28_ } \\
\text { RS03190 }\end{array}$ & EamA family transporter & 3.2 & $\begin{array}{l}3.5 \mathrm{E}- \\
06\end{array}$ & $\begin{array}{l}\text { MAB } \\
0677 C_{C}\end{array}$ & Conserved hypothetical protein & NA & NA \\
\hline $\begin{array}{l}\text { BB28 } \\
\text { RS17050 }\end{array}$ & hypothetical protein & 3.2 & $\begin{array}{l}5.1 \mathrm{E}- \\
32\end{array}$ & $\begin{array}{l}\mathrm{MAB}_{-} \\
3424 \mathrm{C}\end{array}$ & hypothetical protein & NA & NA \\
\hline $\begin{array}{l}\text { BB28_- } \\
\text { RS06235 }\end{array}$ & acyltransferase & 3.1 & $\begin{array}{l}2.7 \mathrm{E}- \\
39\end{array}$ & $\begin{array}{l}\mathrm{MAB}_{-} \\
1297 \mathrm{C}\end{array}$ & hypothetical protein & NA & NA \\
\hline $\begin{array}{l}\text { BB28 } \\
\text { RS01940 }\end{array}$ & $\mathrm{N}$-acetyltransferase & 3.0 & $\begin{array}{l}2.9 \mathrm{E}- \\
11\end{array}$ & $\begin{array}{l}\mathrm{MAB}_{-} \\
0404 \mathrm{C}\end{array}$ & Putative acetyltransferase & NA & NA \\
\hline $\begin{array}{l}\text { BB28_- } \\
\text { RS13285 }\end{array}$ & ferrochelatase & -2.1 & $\begin{array}{l}4.5 \mathrm{E}- \\
40\end{array}$ & $\begin{array}{l}\mathrm{MAB}_{-} \\
2721 \mathrm{C}\end{array}$ & $\begin{array}{l}\text { Ferrochelatase (Protoheme } \\
\text { ferro-lyase) }\end{array}$ & Rv1485 & ferrochelatase \\
\hline $\begin{array}{l}\text { BB28 } \\
\text { RS19235 }\end{array}$ & $\begin{array}{l}\text { alpha-hydroxy-acid oxidizing } \\
\text { enzyme }\end{array}$ & -2.1 & $\begin{array}{l}2.9 \mathrm{E}- \\
35\end{array}$ & $\begin{array}{l}\mathrm{MAB}_{-} \\
3834 \mathrm{C}\end{array}$ & $\begin{array}{l}\text { Possible L-lactate } \\
\text { dehydrogenase (cytochrome) } \\
\text { LIdD1 }\end{array}$ & Rv0694 & $\begin{array}{l}\text { mycofactocin system heme/ } \\
\text { flavin oxidoreductase MftD }\end{array}$ \\
\hline $\begin{array}{l}\text { BB28_- } \\
\text { RS08645 }\end{array}$ & epoxide hydrolase & -2.2 & $\begin{array}{l}2.4 \mathrm{E}- \\
07\end{array}$ & $\begin{array}{l}\text { MAB } \\
1628 \mathrm{c}\end{array}$ & hypothetical protein & NA & NA \\
\hline $\begin{array}{l}\text { BB28_- } \\
\text { RS13295 }\end{array}$ & beta-ketoacyl-ACP reductase & -2.3 & $\begin{array}{l}3.4 \mathrm{E}- \\
56\end{array}$ & $\begin{array}{l}\mathrm{MAB}_{-} \\
2723 \mathrm{C}\end{array}$ & 3-oxoacyl- & $\operatorname{Rv} 1483$ & 3-oxoacyl-ACP reductase FabG \\
\hline $\begin{array}{l}\text { BB28_- } \\
\text { RS13290 }\end{array}$ & $\begin{array}{l}\text { enoyl-acyl-carrier-protein } \\
\text { reductase Fabl }\end{array}$ & -2.4 & $\begin{array}{l}2.0 \mathrm{E}- \\
60\end{array}$ & $\begin{array}{l}\text { MAB } \\
2722 C\end{array}$ & $\begin{array}{l}\text { Enoyl-(acyl-carrier-protein) } \\
\text { reductase (NADH) }\end{array}$ & Rv1484 & $\begin{array}{l}\mathrm{NADH} \text {-dependent enoyl-ACP } \\
\text { reductase }\end{array}$ \\
\hline
\end{tabular}


Table 4 Top 20 upregulated and downregulated M. chelonae genes in the double lysogen (BPs, McProf) relative to WT M. chelonae (McProf) (Continued)

\begin{tabular}{|c|c|c|c|c|c|c|c|}
\hline $\begin{array}{l}\mathrm{MCH}^{\mathrm{a}} \\
\text { gene ID }\end{array}$ & Predicted function $^{\mathbf{b}}$ & $\log 2 \mathrm{FC}^{\mathrm{c}}$ & FDR $^{d}$ & $\begin{array}{l}\text { MAB }^{\mathrm{e}} \\
\text { Gene ID }\end{array}$ & MAB Gene Description & $\begin{array}{l}\text { MTB }^{f} \\
\text { Gene } \\
\text { ID }\end{array}$ & MTB Gene Description \\
\hline $\begin{array}{l}\mathrm{BB} 28- \\
\mathrm{RS} 08640\end{array}$ & hypothetical protein & -2.4 & $\begin{array}{l}2.6 \mathrm{E}- \\
04\end{array}$ & NA & NA & NA & NA \\
\hline $\begin{array}{l}\text { BB28__ } \\
\text { RS19655 }\end{array}$ & universal stress protein & -2.7 & $\begin{array}{l}1.2 \mathrm{E}- \\
03\end{array}$ & $\begin{array}{l}\text { MAB_ } \\
3904\end{array}$ & hypothetical protein & Rv2028c & universal stress protein \\
\hline $\begin{array}{l}\text { BB28_ } \\
\text { RS16545 }\end{array}$ & acyl-ACP desaturase & -2.9 & $\begin{array}{l}1.3 \mathrm{E}- \\
75\end{array}$ & $\begin{array}{l}\mathrm{MAB}_{-} \\
3354\end{array}$ & Probable acyl- & NA & NA \\
\hline $\begin{array}{l}\text { BB28_- } \\
\text { RS05070 }\end{array}$ & cytochrome c oxidase subunit I & -3.2 & $\begin{array}{l}2.8 \mathrm{E}- \\
16\end{array}$ & $\begin{array}{l}\text { MAB } \\
1042 C\end{array}$ & $\begin{array}{l}\text { Probable cytochrome c oxidase } \\
\text { polypeptide I }\end{array}$ & NA & NA \\
\hline $\begin{array}{l}\text { BB28 } \\
\text { RS11065 }\end{array}$ & iron $A B C$ transporter permease & -4.0 & $\begin{array}{l}3.8 \mathrm{E}- \\
16\end{array}$ & NA & NA & NA & NA \\
\hline $\begin{array}{l}\text { BB28_- } \\
\text { RS01880 }\end{array}$ & $\begin{array}{l}\text { DUF58 domain-containing } \\
\text { protein }\end{array}$ & -6.2 & $\begin{array}{l}5.8 \mathrm{E}- \\
06\end{array}$ & $\begin{array}{l}\text { MAB_} \\
0388 C\end{array}$ & hypothetical protein & Rv3693 & membrane protein \\
\hline $\begin{array}{l}\mathrm{BB} 28 \\
\mathrm{RS} 01835\end{array}$ & glycerol uptake glpF & -6.2 & $\begin{array}{l}4.5 \mathrm{E}- \\
06\end{array}$ & $\begin{array}{l}\mathrm{MAB}_{-} \\
0381\end{array}$ & $\begin{array}{l}\text { Glycerol uptake facilitator } \\
\text { protein (GlpF) }\end{array}$ & NA & NA \\
\hline $\begin{array}{l}\text { BB28_- } \\
\text { RS01885 }\end{array}$ & MoxR family ATPase & -6.5 & $\begin{array}{l}1.2 \mathrm{E}- \\
06\end{array}$ & $\begin{array}{l}\text { MAB_} \\
0389 C\end{array}$ & Putative regulatory protein & Rv3692 & $\begin{array}{l}\text { methanol dehydrogenase } \\
\text { transcriptional regulator MoxR }\end{array}$ \\
\hline $\begin{array}{l}\text { BB28_- } \\
\text { RS01875 }\end{array}$ & stage II sporulation protein M & -6.6 & $\begin{array}{l}1.2 \mathrm{E}- \\
06\end{array}$ & $\begin{array}{l}\text { MAB_- } \\
0387\end{array}$ & hypothetical protein & Rv3694c & transmembrane protein \\
\hline $\begin{array}{l}\text { BB28_- } \\
\text { RS24340 }\end{array}$ & RDD family protein & -7.0 & $\begin{array}{l}2.4 \mathrm{E}- \\
07\end{array}$ & $\begin{array}{l}\text { MAB_ } \\
0386 C\end{array}$ & hypothetical protein & Rv3695 & membrane protein \\
\hline $\begin{array}{l}\mathrm{BB} 28- \\
\mathrm{RS} 01830\end{array}$ & KR domain-containing protein & -7.1 & $\begin{array}{l}1.5 \mathrm{E}- \\
07\end{array}$ & $\begin{array}{l}\text { MAB_- } \\
0380\end{array}$ & $\begin{array}{l}\text { Probable short-chain } \\
\text { dehydrogenase/reductase }\end{array}$ & NA & NA \\
\hline $\begin{array}{l}\text { BB28_- } \\
\text { RS01890 }\end{array}$ & $\begin{array}{l}\text { DUF4350 domain-containing } \\
\text { protein }\end{array}$ & -7.3 & $\begin{array}{l}4.6 \mathrm{E}- \\
08\end{array}$ & $\begin{array}{l}\text { MAB_ } \\
\text { O390C }\end{array}$ & hypothetical protein & Rv3691 & hypothetical protein \\
\hline $\begin{array}{l}\text { BB28_- } \\
\text { RS01900 }\end{array}$ & membrane protein & -7.8 & $\begin{array}{l}2.0 \mathrm{E}- \\
09\end{array}$ & $\begin{array}{l}\mathrm{MAB}_{-} \\
0392 \mathrm{C}\end{array}$ & hypothetical protein & Rv3689 & transmembrane protein \\
\hline $\begin{array}{l}\mathrm{BB} 28- \\
\mathrm{RS} 01845\end{array}$ & $\begin{array}{l}\text { PadR family transcriptional } \\
\text { regulator }\end{array}$ & -8.3 & $\begin{array}{l}1.4 \mathrm{E}- \\
10\end{array}$ & $\begin{array}{l}\text { MAB_} \\
0383 C\end{array}$ & $\begin{array}{l}\text { Putative transcriptional } \\
\text { regulator, PadR-like }\end{array}$ & NA & NA \\
\hline $\begin{array}{l}\text { BB28_- } \\
\text { RS01840 }\end{array}$ & glycerol kinase & -9.0 & $\begin{array}{l}1.1 \mathrm{E}- \\
12\end{array}$ & $\begin{array}{l}\text { MAB_- } \\
0382\end{array}$ & Glycerol kinase (GlpK) & Rv3696c & glycerol kinase \\
\hline
\end{tabular}

${ }^{\mathrm{a}} \mathrm{MCH}=$ Mycobacterium chlelonae

${ }^{\mathrm{b}}$ Genes that belong to the WhiB7 regulon are in bold

'Log2 Fold Change for the double lysogen (+BPs+McProf) of $M$. chelonae

${ }^{\mathrm{d}} \mathrm{FDR}=$ False Discovery Rate

${ }^{\mathrm{e}} \mathrm{MAB}=$ Mycobacterium abscessus

${ }^{\mathrm{f}} \mathrm{MTB}=$ Mycobacterium tuberculosis

lysogen (BPs, McProf), and non-lysogen ( $\triangle$ McProf) and compared to that of the WT strain (McProf) (Fig. 5). Although whiB7 expression was slightly elevated in the nonlysogen (2-fold) and BPs single lysogen (4-fold) strains relative to the WT strain (McProf), the dramatic increase in whiB7 expression ( 40-fold) only occurred in $M$. chelonae carrying both prophages (BPs, McProf). The elevated whiB7 expression occurred in the absence of known inducers of whiB7, such as $\mathrm{ACI}$, which suggests BPs interacts with prophage McProf, resulting in whiB7 induction. The elevated expression of whiB7 in the double lysogen likely explains the increased resistance to AMK and TOB in the absence of ACI treatment (Table 1 and Fig. 2).

\section{Sub-lethal concentrations of $A C I$ but not AMK induce} whiB7 expression in the double lysogen of $M$. chelonae We were surprised that the $M$. chelonae (McProf) strain had the lowest expression of whiB7 expression among the four strains given that it had higher AMK resistance, both in the presence and absence of ACI, than the two strains that lack McProf. We reasoned this may be due to whiB7-independent intrinsic resistance, such as cell wall permeability, and/or whiB7 induction in the presence of AMK, which is a more potent inducer of whiB7 than ACI [12]. Likewise, we wondered if the heightened viability observed in the single and double McProf lysogen strains in the presence of $\mathrm{AMK}$ and $\mathrm{ACI}$ was due to increased whiB7 
Table 5 WhiB7 regulon genes upregulated in M. chelonae double lysogens relative to the WT M. chelonae (McProf)

\begin{tabular}{|c|c|c|c|c|c|}
\hline $\begin{array}{l}\text { MCH gene } \\
\text { ID }\end{array}$ & Predicted function & $\begin{array}{l}\log 2 \\
F^{b}\end{array}$ & FDR $^{c}$ & $\begin{array}{l}\text { MAB }^{\text {d }} \text { gene } \\
\text { ID }\end{array}$ & Predicted Function \\
\hline $\begin{array}{l}\text { BB28_ } \\
\text { RS19005 }\end{array}$ & hypothetical protein & 6.1 & $\begin{array}{l}9.1 \mathrm{E}- \\
18\end{array}$ & MAB_3786C & Hypothetical protein \\
\hline $\begin{array}{l}\text { BB28_ } \\
\text { RS23100 }\end{array}$ & $\mathrm{N}$-acetyltransferase & 5.6 & $\begin{array}{l}4.4 \mathrm{E}- \\
38\end{array}$ & MAB_4621C & Putative acetyltransferase \\
\hline $\begin{array}{l}\text { BB28_ } \\
\text { RS23095 }\end{array}$ & hypothetical protein & 5.2 & $\begin{array}{l}2.8 \mathrm{E}- \\
35\end{array}$ & MAB_4620C & Hypothetical protein \\
\hline $\begin{array}{l}\text { BB28_ } \\
\text { RS17590 }\end{array}$ & WhiB7 transcriptional regulator & 4.7 & $\begin{array}{l}1.3 \mathrm{E}- \\
73\end{array}$ & MAB_3508c & Putative transcriptional regulator \\
\hline $\begin{array}{l}\text { BB28_ } \\
\text { RS05390 }\end{array}$ & GNAT family N-acetyltransferase (eis1) & 4.1 & $\begin{array}{l}5.8 \mathrm{E}- \\
12\end{array}$ & MAB_1125c & Hypothetical acetyltransferase, GNAT family \\
\hline $\begin{array}{l}\text { BB28_ } \\
\text { RS06460 }\end{array}$ & NAD(P)-dependent oxidoreductase & 3.4 & $\begin{array}{l}1.2 \mathrm{E}- \\
21\end{array}$ & MAB_1344C & $\begin{array}{l}\text { Putative DTDP-glucose-4,6-dehydratase-related } \\
\text { protein }\end{array}$ \\
\hline $\begin{array}{l}\text { BB28_ } \\
\text { RS11540 }\end{array}$ & ABC transporter ATP-binding protein & 3.3 & $\begin{array}{l}3.5 \mathrm{E}- \\
64\end{array}$ & MAB_2355c & Putative ABC transporter ATP-binding protein \\
\hline $\begin{array}{l}\text { BB28_ } \\
\text { RS22650 }\end{array}$ & GNAT family $\mathrm{N}$-acetyltransferase (eis2) & 3.3 & $\begin{array}{l}1 \mathrm{E}- \\
176\end{array}$ & MAB_4532C & $\mathrm{N}$ - acetyltransferase( eis2) \\
\hline $\begin{array}{l}\text { BB28__ } \\
\text { RS06750 }\end{array}$ & tap multidrig efflux transporter & 3.3 & $\begin{array}{l}7.3 \mathrm{E}- \\
35\end{array}$ & MAB_1409C & Putative drug antiporter protein precursor \\
\hline $\begin{array}{l}\text { BB28_ } \\
\text { RS13560 }\end{array}$ & TetV Efflux Pump & 3.3 & $\begin{array}{l}9.8 \mathrm{E}- \\
94\end{array}$ & MAB_2780C & TetV Efflux Pump \\
\hline $\begin{array}{l}\text { BB28_ } \\
\text { RS20470 }\end{array}$ & $\begin{array}{l}\text { pyridoxamine } 5 \text { '-phosphate oxidase family } \\
\text { protein }\end{array}$ & 3.2 & $\begin{array}{l}4.0 \mathrm{E}- \\
29\end{array}$ & MAB_4054C & Hypothetical protein \\
\hline $\begin{array}{l}\text { BB28_ } \\
\text { RS17050 }\end{array}$ & hypothetical protein & 3.2 & $\begin{array}{l}5.1 \mathrm{E}- \\
32\end{array}$ & MAB_3424C & hypothetical protein \\
\hline $\begin{array}{l}\text { BB28_ } \\
\text { RS01940 }\end{array}$ & $\mathrm{N}$-acetyltransferase & 3.0 & $\begin{array}{l}2.9 \mathrm{E}- \\
11\end{array}$ & MAB_0404c & Putative acetyltransferase \\
\hline $\begin{array}{l}\text { BB28_ } \\
\text { RS09285 }\end{array}$ & ABC transporter ATP-binding protein & 2.9 & $\begin{array}{l}2.7 \mathrm{E}- \\
07\end{array}$ & MAB_1846 & Putative $A B C$ transporter ATP-binding protein \\
\hline $\begin{array}{l}\text { BB28_ } \\
\text { RS12530 }\end{array}$ & $18 \mathrm{kDa}$ antigen (HSP 16.7) & 2.3 & $\begin{array}{l}2.5 \mathrm{E}- \\
31\end{array}$ & MAB_3467C & $18 \mathrm{kDa}$ antigen (HSP 16.7) \\
\hline $\begin{array}{l}\text { BB28_ } \\
\text { RS03635 }\end{array}$ & EamA/RhaT family transporter & 2.0 & $\begin{array}{l}1.4 \mathrm{E}- \\
04\end{array}$ & MAB_0766 & $\begin{array}{l}\text { Hypothetical conserved integral membrane } \\
\text { protein }\end{array}$ \\
\hline $\begin{array}{l}\text { BB28_ } \\
\text { RS18890 }\end{array}$ & membrane protein & 1.8 & $\begin{array}{l}1.9 \mathrm{E}- \\
17\end{array}$ & MAB_3762 & hypothetical protein \\
\hline $\begin{array}{l}\text { BB28_ } \\
\text { RS17595 }\end{array}$ & hypothetical protein & 1.8 & $\begin{array}{l}3.6 \mathrm{E}- \\
41\end{array}$ & MAB_3509c & Hypothetical protein \\
\hline $\begin{array}{l}\text { BB28_ } \\
\text { RS06440 }\end{array}$ & TIGR00730 family Rossman fold protein & 1.6 & $\begin{array}{l}2.7 \mathrm{E}- \\
08\end{array}$ & MAB_1340 & hypothetical protein \\
\hline $\begin{array}{l}\text { BB28_ } \\
\text { RS13900 }\end{array}$ & methyltransferase domain-containing protein & 1.6 & $\begin{array}{l}1.6 \mathrm{E}- \\
13\end{array}$ & MAB_2845 & Probable trans-aconitate methyltransferase \\
\hline $\begin{array}{l}\text { BB28_ } \\
\text { RS05350 }\end{array}$ & hypothetical protein & 1.6 & $\begin{array}{l}2.2 \mathrm{E}- \\
27\end{array}$ & MAB_1117c & Hypothetical protein \\
\hline $\begin{array}{l}\text { BB28_ } \\
\text { RS14985 }\end{array}$ & GTPase HflX & 1.5 & $\begin{array}{l}8.4 \mathrm{E}- \\
33\end{array}$ & MAB_3042C & Probable GTP-binding protein HfIX \\
\hline $\begin{array}{l}\text { BB28 } \\
\text { RS20665 }\end{array}$ & isocitrate lyase (AceA) & 1.5 & $\begin{array}{l}3.9 \mathrm{E}- \\
12\end{array}$ & MAB_4095C & Isocitrate lyase (AceA) \\
\hline $\begin{array}{l}\text { BB28_- } \\
\text { RS06230 }\end{array}$ & hypothetical protein & 1.5 & $\begin{array}{l}2.7 \mathrm{E}- \\
03\end{array}$ & MAB_1296 & hypothetical protein \\
\hline $\begin{array}{l}\text { BB28__ } \\
\text { RS06840 }\end{array}$ & hypothetical protein & 1.5 & $\begin{array}{l}1.1 \mathrm{E}- \\
05\end{array}$ & MAB_1413 & hypothetical protein \\
\hline $\begin{array}{l}\text { BB28_ } \\
\text { RS00915 }\end{array}$ & cation transporter & 1.5 & $\begin{array}{l}4.6 \mathrm{E}- \\
29\end{array}$ & MAB_0183c & Putative cation transporter \\
\hline BB28_ & LysE family translocator & 1.5 & 3.7E- & MAB_3913 & Putative translocator \\
\hline
\end{tabular}


Table 5 WhiB7 regulon genes upregulated in M. chelonae double lysogens relative to the WT M. chelonae (McProf) (Continued)

\begin{tabular}{|c|c|c|c|c|c|}
\hline $\begin{array}{l}\mathrm{MCH}^{\mathrm{a}} \text { gene } \\
\text { ID }\end{array}$ & Predicted function & $\begin{array}{l}\log 2 \\
\mathrm{FC}^{\mathrm{b}}\end{array}$ & FDR $^{\mathrm{c}}$ & $\begin{array}{l}\text { MAB }{ }^{d} \text { gene } \\
\text { ID }\end{array}$ & Predicted Function \\
\hline RS19745 & & & 07 & & \\
\hline $\begin{array}{l}\text { BB28__ } \\
\text { RS06445 }\end{array}$ & TIGR00730 family Rossman fold protein & 1.4 & $\begin{array}{l}2.1 \mathrm{E}- \\
06\end{array}$ & MAB_1341 & hypothetical protein \\
\hline $\begin{array}{l}\text { BB28_- } \\
\text { RS12685 }\end{array}$ & aminoglycoside phosphotransferase & 1.1 & $\begin{array}{l}1.6 \mathrm{E}- \\
02\end{array}$ & MAB_4837C & Possible phosphotransferase \\
\hline $\begin{array}{l}\text { BB28_- } \\
\text { RS14560 }\end{array}$ & GNAT family N-acetyltransferase & 1.0 & $\begin{array}{l}2.7 \mathrm{E}- \\
17\end{array}$ & MAB_2959 & Putative acetyltransferase \\
\hline
\end{tabular}

${ }^{\mathrm{a}} \mathrm{MCH}=$ Mycobacterium chlelonae

${ }^{\mathrm{b}}$ Log2 Fold Change for the double lysogen (+BPs+McProf) of $M$. chelonae

${ }^{\mathrm{C}} \mathrm{FDR}=$ False Discovery Rate

${ }^{\mathrm{d}} \mathrm{MAB}=$ Mycobacterium abscessus

expression. We therefore measured whiB7 expression in all four strains in the presence and absence of sublethal concentrations of ACI $(75 \mu \mathrm{M})$ or AMK $(16.7 \mu \mathrm{M})$ (Fig. 6).

$\mathrm{ACI}$ treatment resulted in increased whiB7 expression in all four strains relative to untreated strains (Fig. 6a). Expression of whiB7 was highest in the double lysogen strain (BPs, McProf) treated with ACI which correlates with the observed AMK resistance of this strain. whiB7 expression in the single and non-lysogen strain increased with ACI treatment; however, the relative levels of whiB7 expression did not correlate with AMK resistance (Fig. 2a). Although the fold-increase of whiB7 in ACItreated strains relative to control strains was highest in the WT strain (McProf) (9.5-fold) whiB7 was lower than that of the ACI-treated BPs single lysogen, which demonstrated lower AMK resistance.

To determine if exposure to AMK also contributes to whiB7 expression in each of the four strains, whiB7 expression was determined in each of the strains in the presence and absence of sub-lethal concentrations of AMK $(16.7 \mu \mathrm{M})$. Strains that lack the McProf prophage had the greatest increase in whiB7 expression in response to AMK treatment. The non-lysogen and BPs single lysogen had 28- and 7-fold increases in whiB7 expression in response to AMK treatment, respectively (Fig. 6b). AMK had less of an effect on whiB7 expression in strains carrying McProf. AMK treatment resulted in a 3.5 -fold increase in whiB7 expression in the single McProf lysogen and no significant increase in whiB7 expression in the double lysogen. It's possible that AMK doesn't result in strong induction of whiB7 expression in the McProf-carrying strains due to cell wall permeability and/or efflux, and if so, this could also explain the AMK-resistant phenotypes observed in the single McProf and double lysogen strains.

\section{Organization of the McProf prophage genome}

To better understand how the two prophages, BPs, and McProf, may be interacting to alter whiB7 expression, we characterized the McProf genome and examined viral gene expression profiles from both McProf and BPs prophage genomes in the double lysogen. The McProf genome is $67,657 \mathrm{bp}$ in length $(M$. chelonae CCUG 47445 coordinates 1,521,426 - 1,589, 648) and encodes 98 putative genes and no tRNAs (Fig. 7a). The prophage genome is flanked by 45 -bp phage attachment sites, attL and attR (5'- TGCGCCGT CAGGGGCTCGAACCCCGGACCCGCTGATTAAGAGTCA).

The right attachment site, attR, overlaps a leftward oriented tRNA-Lys (BB28_RS07905). Located adjacent to the left attachment site, attL, is a rightward transcribed tyrosine integrase (gp1), one gene of unknown function (gp2) and a leftward transcribed gene, gp3, that is likely to be the immunity repressor, as it shares high amino acid sequence similarity with the immunity repressors of singleton mycobacteriophage DS6A (66\%) and cluster K2 mycobacteriophages (70\%) DismalFunk, DismalStressor, Findley, Marcoliusprime and Milly [35]. Gp4 and gp5 both have helixturn-helix DNA binding motifs and encode Cro (control of repressor's operator) and excise, respectively.

Located between attR and the structural genes (gp5182) are genes that are typically expressed during lysogeny [36]. We were unable to predict a function for the majority of these genes; however, we were able to identify an ADP-riboysl glycosylhydrolase (gp86), a helixturn-helix DNA binding protein (gp89), a membrane protein (gp90), and an AAA-ATPase (gp91). Most intriguing is the leftward transcribed gene cassette immediately adjacent to $a t t R$, which encodes proteins that may be secreted by the mycobacterial Type 7 secretion system (T7SS) (Esx-3 or Esx4) (Fig. 7b and c). Gp98 encodes a 105-amino acid gene product that forms four HHpred predicted helical domains with high probability matches to WXG-100 family motifs of T7SS proteins. The gp98 sequence contains a SAG motif, which strays slightly from the conserved WXG motif that is characteristic of T7SS secreted substrates [37]. Gp97 encodes a 732-residue polymorphic toxin that has a WXG-100 


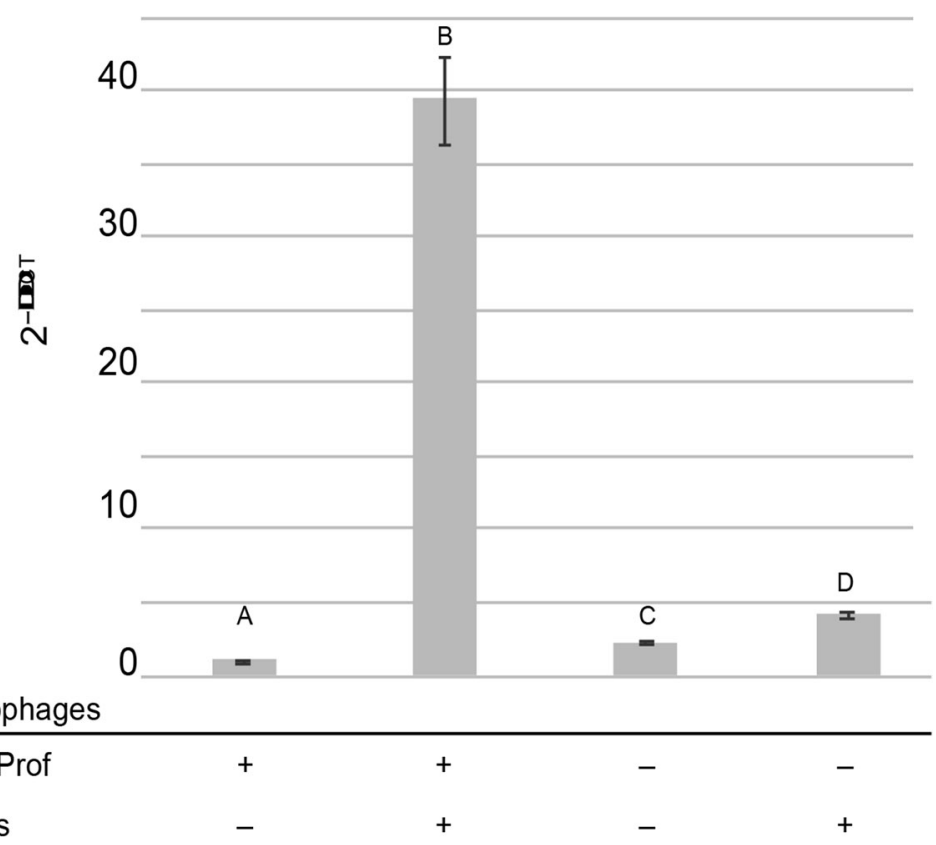

Fig. 5 The average relative expression levels of whiB7 in M. chelonae carrying McProf alone, BPs and McProf, no prophage, and BPs alone as measured with SYBR Green quantitative RT-PCR. Cultures were grown to an $\mathrm{OD}_{600}$ of 1.0 before harvesting RNA in triplicate. Graphs represent average values \pm standard error of the mean with $n=3$ and are representative of two independent trials. Means with different letters are significantly different (Tukey's HSD, $a=0.05$ )

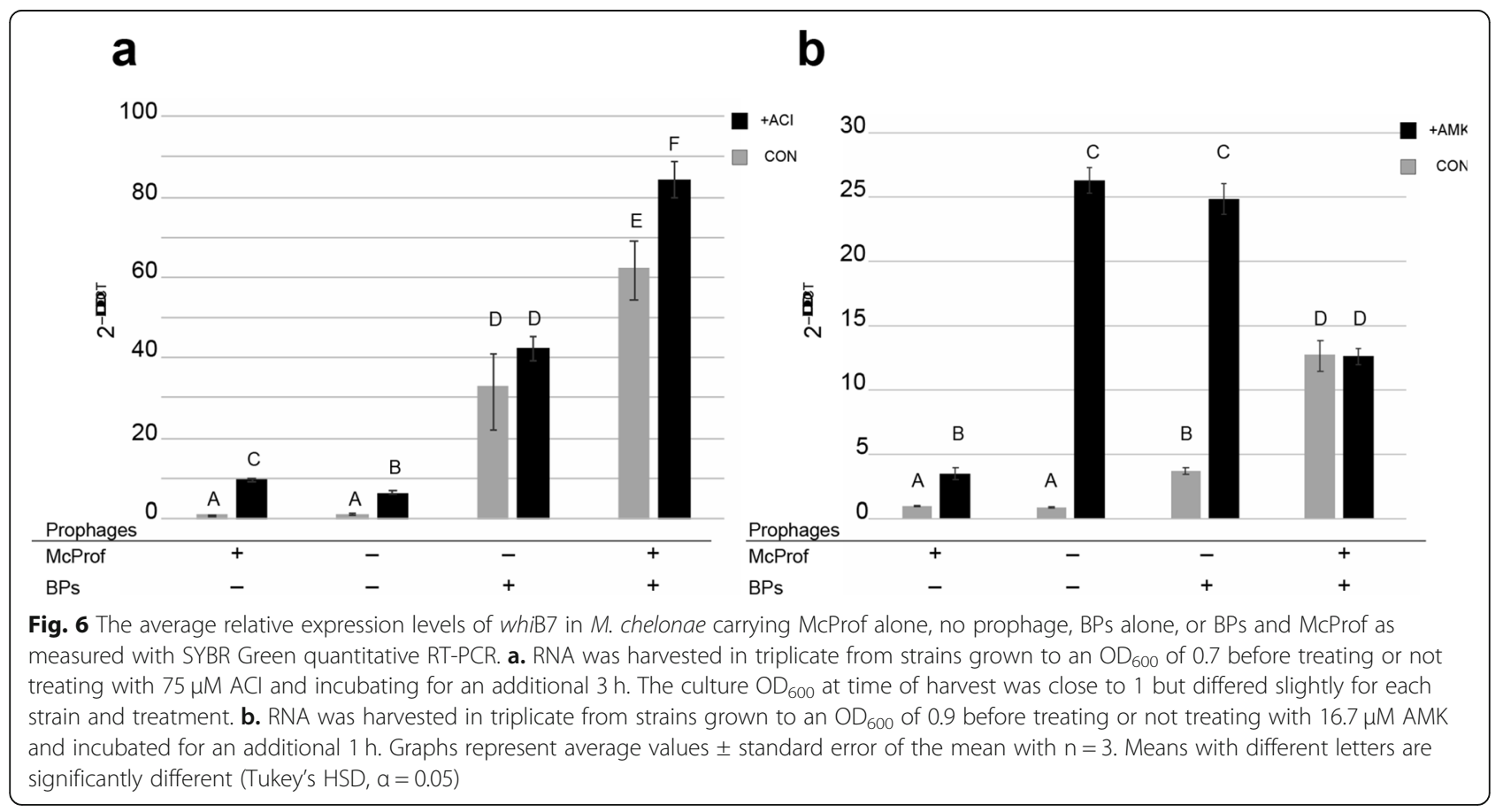




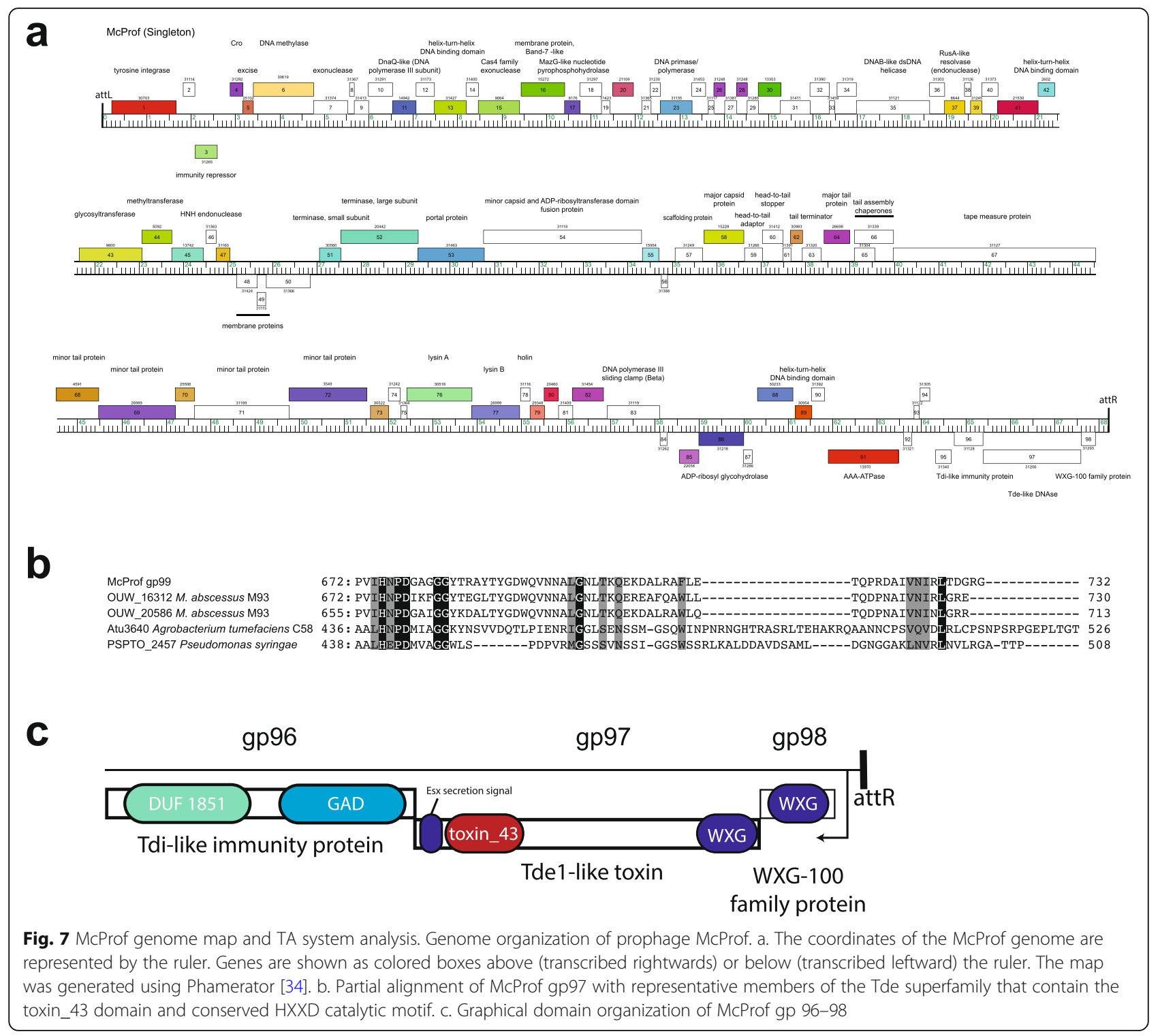

motif in the N-terminus and a possible T7SS secretion signal (YxxxD/E) in the C-terminus [38]. The Cterminus also includes a toxin_43 motif (PF15604.6) and high sequence similarity to the C-terminus of Type 6 secretion system (T6SS) polymorphic toxin, TdeI (Atu4350), found in Agrobacterium tumefaciens [39]. This family of proteins has DNAse activity and shares a conserved HXXD catalytic domain located in the Cterminus (Fig. 7b) [39]. Tde toxins are typically paired with a Tdi immunity protein and a likely immunity protein, gp96, was identified downstream of McProf gp97. McProf gp96 encodes a putative 216-residue protein that contains GAD-like and DUF1851 domains, which are well-conserved domains of Tdi homologs (Fig. 7c) [39].
Although the McProf prophage was identified and characterized in $M$. chelonae, it is closely related to prophages found in the genome sequences of clinical $M$. abscessus isolates. BlastN analysis of the McProf prophage genome in $M$. abscessus-specific databases (e.g. phagesdb.org) identified 25 M. abscessus isolates with McProf-like prophage sequences [35]. The WXG-100 family polymorphic toxin cassette identified in McProf is also prevalent in $M$. abscessus genomes. BlastP analysis of the McProf Tde-like polymorphic toxin (gp97 toxin) results in 100 high-similarity protein alignments to mycobacterial proteins with $91 \%$ matching $M$. abscessus sequences. An initial random screen of 10 of the aligned sequences showed that they were all located in prophage 


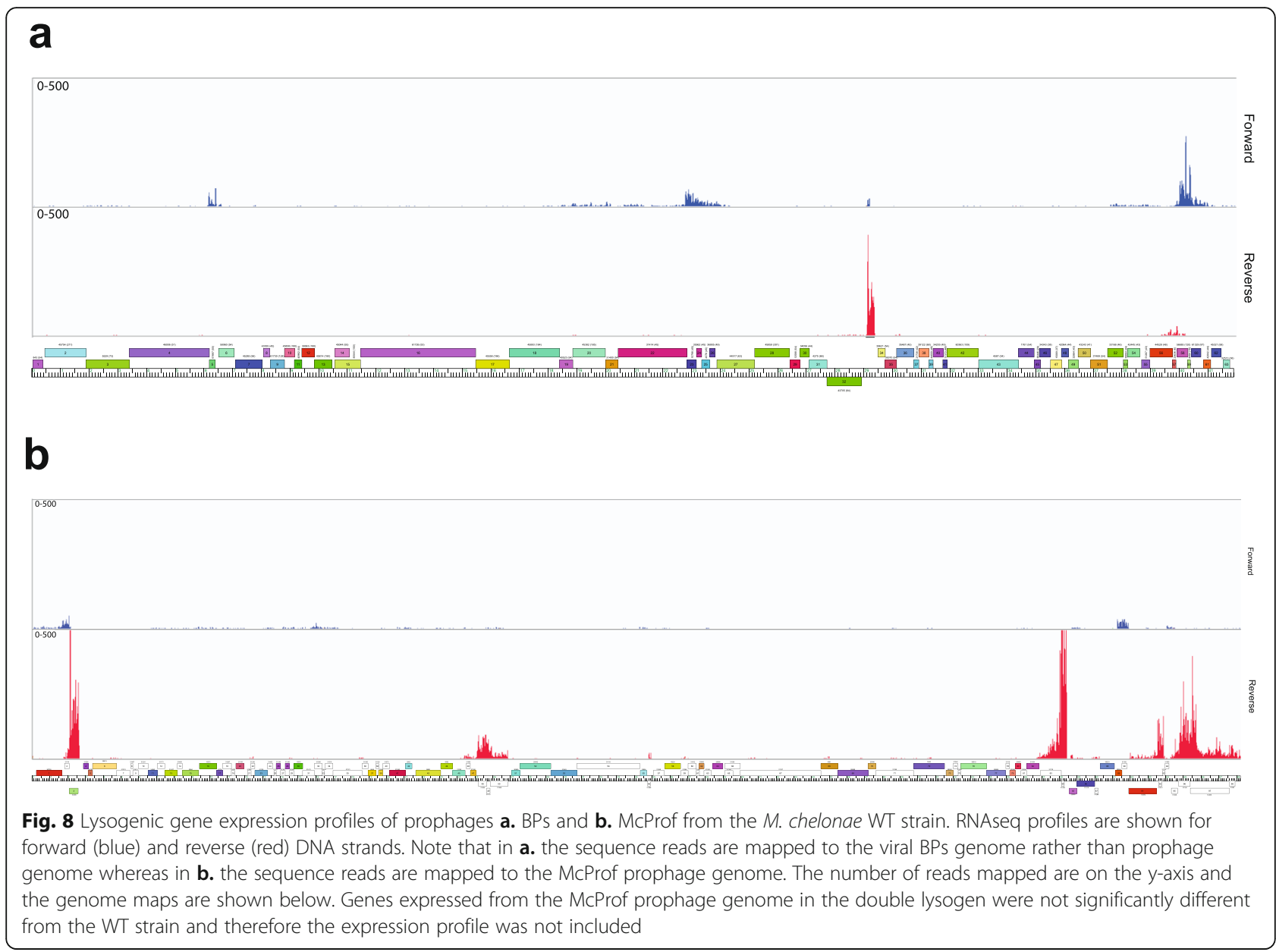

genomes flanked by a WXG-100 family gene and an immunity gene.

\section{Lysogenic gene expression profiles from the BPs and McProf prophage genomes}

To determine if the presence of BPs alters gene expression from the McProf prophage genome, differential expression of McProf genes was examined between the WT strain (McProf) and the double lysogen (BPs, McProf). None of the expressed McProf genes were significantly differentially expressed in the presence of the BPs prophage $(\mathrm{FC}>1.99$ and $\mathrm{FDR}<0.05)$. Because there was no difference in expression profiles, we present below the expression profile of only the McProf prophage from the M. chelonae WT (McProf) strain (Fig. 8b).

The immunity repressors from both the BPs (gp33) and McProf (gp3) genomes are highly expressed during lysogeny of M. chelonae (Fig. 8a). The BPs genome also expresses, gp58, a gene of unknown function that is part of a mycobacteriophage mobile element (MPME1) (Fig. 8a) [28]. There are an additional 15 genes expressed at varying levels from the McProf genome (Fig. 8b). The integrase (gp1) is expressed at low levels and is adjacent to a moderately expressed genes of no known function (gp2). There are three reverse oriented genes, gp48-50, located between the $\mathrm{HNH}$ endonuclease (gp47) and the small subunit terminase (gp51) and a small reverse oriented gene (gp56) adjacent to the scaffolding protein with moderately and low expression, respectively. We were not able to determine functions for these genes; however, gp48 and gp49 do have predicted membrane domains. The remaining genes expressed from the McProf prophage genome are located between the structural genes and attR and many do not have predicted gene functions, including the most highly expressed McProf gene, gp84. There is also strong expression from the gene cassette containing the putative WXG-100 family polymorphic toxin and immunity protein (gp96-98). None of the expressed McProf genes were significantly differentially expressed in the presence of the BPs prophage $(\mathrm{FC}>1.99$ and FDR $<0.05)$.

\section{Discussion}

The incidence of non-tuberculosis mycobacterial disease has increased over the last 20 years [40]. M. abscessus, 
along with $M$. avium, is the major cause of bronchopulmonary infections in cystic fibrosis patients, and is of increasing concern due its high levels of intrinsic antibiotic resistance [9]. CLA and AMK are the two core drugs used to treat $M$. abscessus infections; however, development of resistance to these drugs is common during treatment [9]. Mycobacterial resistance to CLA and AMK are often the result of mutations in $23 \mathrm{~s}$ rRNA or $16 \mathrm{~s}$ rRNA, respectively, but mutations alone do not completely account for AMK and CLA resistant phenotypes in $M$. abscessus clinical isolates [7, 13]. Induction of the whiB7 regulon in mycobacteria is the second major contributor to resistance to AMK and CLA [7]. Heightened expression of whiB7 is consistently observed in extensively resistant $M$. abscessus isolates relative to drug susceptible isolates [7, 13]. Understanding the mechanisms that drive increased expression of whiB7 will be important for improving treatment of resistant mycobacterial infections. The WhiB7 response is highly conserved across all mycobacteria and our studies shows that the WhiB7 regulon in M. chelonae overlaps considerably with that of $M$. abscessus $[12,15]$. Here we describe for the first time that prophages in mycobacteria alter antibiotic resistance and expression of intrinsic antibiotic resistance genes of the whiB7 regulon. This study provides valuable insight into the role prophages play in mycobacterial antibiotic resistance and novel mechanisms of whiB7 induction.

In this report we show for the first time that prophages in mycobacteria can contribute to increased resistance to aminoglycosides AMK and TOB (Table 1; Fig. 1; and Fig. 2). This is similar to the resistance observed in E. coli carrying multiple prophages [1]. Of the two prophages investigated in this study, the naturally occurring prophage, McProf, appears to play the more important role in inducing intrinsic resistance in $M$. chelonae (Table 1; Fig. 1; and Fig. 2). Strains carrying the McProf prophage demonstrated increased AMK resistance relative to the non-lysogen and BPs single lysogen strains in the absence of ACI. The increased AMK resistance observed in McProf carrying strains was further increased by either ACI treatment or the presence of a second prophage, BPs. Enhanced resistance in McProfcarrying strains in response to $\mathrm{ACI}$ treatment was also observed in the TOB MIC assays. We know that subinhibitory concentrations of ribosome targeting antibiotics, such as $\mathrm{ACI}$, induce whiB7 expression and intrinsic drug resistance and we observed this in the nonlysogen ( $\Delta$ McProf) strain (Fig. 2) [14, 15]. The presence of McProf appears to enhance the effect of ACI on resistance in the AMK and TOB assays (Figs. 2 and 3).

The dramatically higher whiB7 expression in the strain carrying both prophages (BPs, McProf) likely contributes to the heightened AMK and TOB resistance observed in the double lysogen (Figs. 2 and 4; Tables 4 and 5). We observed high whiB7 expression in the double lysogen in the absence of antibiotics or other conditions known to induce whiB7, revealing prophage as a novel mechanism of inducing whiB7 expression and intrinsic antibiotic resistance. Also upregulated in the double lysogen are whiB7 regulon genes that can explain the increased resistance to aminoglycosides AMK and TOB [41]. The GNAT acetyltransferase, eis2, and tap, a multidrug efflux pump, were each upregulated $\sim 10$-fold in the double lysogen and confer resistance to aminoglycosides [12, 42, 43]. $2^{\prime}$-N-acetyltransferase AAC ( $\left.2^{\prime}\right)$ also contributes to resistance to TOB and AMK, however this gene (BB28_ RS22055) was not significantly upregulated in our data set [44]. It is possible that other $\mathrm{N}$-acetyltransferases (BB28_RS23100, BB28_RS01940, BB28_RS14560), aminoglycoside phosphotransferases (BB28_RS12685), or potential efflux pumps (BB28_11540) upregulated in our dataset contributed to AMK and TOB resistance of the double lysogen (Table 5). Tap, along with TetV (BB28_ RS13560) target tetracycline efflux, however, we did not consistently see an increase in TET resistance across all our MIC trials [45, 46]. Although M. chelonae lacks an erm gene, there was a slight elevation in the whiB7 regulon gene, $h f l x$, but this did not result in a significant change in CLA resistance [32].

Other mechanisms of intrinsic resistance also likely contribute to the AMK and TOB resistance observed in the McProf-carrying strains. The McProf-carrying strains demonstrated the highest AMK resistance in the presence and absence of ACI treatment. Although whiB7 expression was highest in the double lysogen (BPs, McProf) treated with ACI among the four strains, whiB7 expression levels in the single McProf strain did not correlate with its relative AMK resistance among the four strains. AMK is also a potent inducer of whiB7 expression in mycobacteria; however, AMK had little to no effect on whiB7 expression in strains carrying McProf [12]. The strong induction of whiB7 with AMK treatment in strains that lack McProf suggests that the presence of the McProf prophage may affect cell wall permeability. A decrease in cell wall permeability in McProf-carrying strains would likely contribute to the observed AMK resistance in these strains. Investigating differences in cell wall permeability in the presence and absence of McProf will be important for understanding the effect of prophages on drug resistance.

We do not yet know how the two prophages, BPs and McProf, interact to alter whiB7 expression in the double lysogen strain. The McProf genome appears to only express genes through lysogenic infection of $M$. chelonae, whereas BPs can carry out lysogenic and lytic infection (via induction) in a population of double lysogen cells. It's therefore possible that either lytic or lysogenic gene 
expression from BPs interacts with any of the 16 genes products expressed from the McProf genome through an unknown mechanism to alter whiB7 expression. Each of the 16 expressed McProf genes will be investigated for a potential role in altered whiB7 expression; however, the genes in the WXG-100 family polymorphic toxin cassette are strong candidates. Activated toxin systems could potentially act as a trigger to the WhiB7 stress response. Sub-inhibitory concentrations of antibiotics and BPs phage infection both enhanced antibiotic resistance in $M$. chelonae in the presence of prophage McProf (Figs. 1 and 4), conditions also known to activate toxin/ antitoxin systems [47-51]. Toxin/antitoxin systems are also known to function as stress response modules and regulators of adaptive responses to stresses associated with host environment and drug treatment [49]. Further, toxin/antitoxin systems are abundant in pathogenic mycobacteria and are more highly expressed in the most virulent strains of $M$. tuberculosis [49]. In comparison there are relatively few toxin/antitoxin systems in nonpathogenic mycobacteria [47]. Toxin/antitoxin systems also stabilize replicative elements (e.g. plasmids and prophage) and defend against phage lytic infection [52, 53]. The increased stability of the BPs prophage in the presence of McProf compared to BPs lysogens in the cured $M$. chelonae ( $\Delta \mathrm{McProf}$ ) and its reported instability in $M$. smegmatis strains $[28,29]$ suggests that such system encoded by McProf is active.

\section{Conclusions}

We have established that dramatic increases in whiB7 expression and AMK resistance only occurs in M. chelonae strains carrying a type of prophage that is also found naturally in $M$. abscessus strains. The observed AMK resistance in the presence of prophage McProf is further enhanced by exposure to sub-inhibitory concentrations or by the presence of a second prophage, BPs. Pathogenic mycobacteria typically carry one or more prophages that are capable of induction and in infected tissues are likely exposed to lytic phage infection and sub-inhibitory concentrations of antibiotics during treatment. Our novel research findings indicate that prophage could be drivers of important intrinsic antibiotic resistance genes in response to such stresses. To determine the mechanism by which phage alter intrinsic antibiotic resistance in mycobacteria, we are exploring the function and impact of specific phage genes on expression of whiB7 in the presence of various environmental stressors.

\section{Methods}

\section{Bacterial and viral strains}

Mycobacterium chelonae (ATCC 35,752 , American Type Culture Collection, Manassas, VA) was cultivated at
$30{ }^{\circ} \mathrm{C}$ with shaking at 200 RPM in liquid Middlebrook $7 \mathrm{H} 9$ (BD, Sparks, MD) supplemented with $10 \%$ ADO (Bovine Serum Albumin, Dextrose, Oleic Acid) in the absence of antibiotics unless indicated. Tween 80 to a final concentration of $0.05 \%$ was added to the media to avoid clumping but was omitted in MIC experiments and any experiments involving phage infection. The wildtype (WT) strain of $M$. chelonae carries a prophage that we have named McProf and we refer to this strain as M. chelonae (McProf) (Table 2). Cloning was carried out in chemically competent Escherichia coli DH5 $\alpha$ (New England Biolabs (NEB), Ipswich, MA). Kanamycin was used for selection of the expression vector pST-KT at $250 \mu \mathrm{g} \mathrm{ml}^{-1}$. Strains used in this study are listed in Table 2.

Bacteriophage BPs was obtained from the Hatfull Laboratory [28]. Phage lysates were propagated through plaque assays in either M. smegmatis $\mathrm{MC}^{2} 155$ or $M$. chelonae (McProf), or a cured strain of $M$. chelonae that we refer to as the non-lysogen $M$. chelonae strain ( $\Delta$ McProf) (Table 2) [54]. Briefly, 0.5-ml aliquots of late$\log$ phase bacteria were incubated with serially-diluted phage samples for $15 \mathrm{~min}$ before plating in $4.5 \mathrm{ml}$ of 7H9 top agar containing $0.45 \%$ agar onto $7 \mathrm{H} 10$ agar plates. Phage stocks were created by flooding plates with nearly confluent bacterial lysis with phage buffer (10 $\mathrm{mM}$ Tris/ $\mathrm{HCl} \mathrm{pH} 7.5,10 \mathrm{mM} \mathrm{MgSO}_{4}, 1 \mathrm{mM} \mathrm{CaCl}$, $68.5 \mathrm{mM} \mathrm{NaCl}$ ).

\section{Curing of M. chelonae WT strain}

A recombinant strain of $M$. chelonae (McProf) that overexpresses the McProf excision (xis) gene (McProf gp5) was created by cloning a 292-bp G-block (Integrated DNA Techonologies, Coralville, IA) encoding the xis gene into the mycobacterial expression vector, $\mathrm{pST}-\mathrm{KT}$ using Gibson Assembly (NEB, Ipswich, MA) [30]. Recombinant plasmids were sequenced to verify the presence of the xis sequence prior to electroporating into competent WT M. chelonae (McProf) [55]. Cultures of recombinant $M$. chelonae carrying $\mathrm{pST}-\mathrm{KT} \_x i$ were grown in $10-\mathrm{mL}$ volumes for $48 \mathrm{~h}$ at $30^{\circ} \mathrm{C}$ with shaking. Optical density was measured at a wavelength of 600 $\mathrm{nm}$, and samples sub-cultured to an optical density of 0.05 . Cultures were then grown to an optical density of 0.6 and treated with $500 \mu \mathrm{g} \mathrm{mL}^{-1}$ of anhydrotetracycline (ATc) prepared in dimethylsulfoxide (DMSO) or an equivalent volume of DMSO. Cultures were incubated at $30^{\circ} \mathrm{C}$ with shaking for an additional $72 \mathrm{~h}$. A $0.5-\mathrm{mL}$ sample of each culture was harvested and serially diluted in 7H9-OAD. Dilutions were plated onto 7H10-OAD supplemented with $250 \mu \mathrm{g} \mathrm{mL}^{-1}$ of kanamycin in $100-\mu \mathrm{L}$ volumes and incubated at $30^{\circ} \mathrm{C}$ for $5 \mathrm{~d}$. Resulting colonies were PCR screened for the loss of prophage McProf using a set of four primers that amplify either the bacterial $a t t B$ site, indicating loss of the prophage, or 
Table $6 \mathrm{qPCR}$ primers used in this study

\begin{tabular}{|c|c|c|c|c|c|}
\hline Target & Primers & Sequence (5' to $\left.3^{\prime}\right)$ & $\begin{array}{l}\mathrm{Tm} \\
\left({ }^{\circ} \mathrm{C}\right)\end{array}$ & $\begin{array}{l}\% \\
\text { GC }\end{array}$ & $\begin{array}{l}\text { amplicon size } \\
\text { (bp) }\end{array}$ \\
\hline \multirow[t]{2}{*}{ Forward and reverse primers targeting whiB7 (BB28_RS17590) } & WhiB7_qPCR_F4 & ACTTTCCGCGAACCACAG & 55.6 & 55.6 & 81 \\
\hline & $\begin{array}{l}\text { WhiB7_qPCR_ } \\
\text { R1a }\end{array}$ & ATGATGACCGTCGAAGTGG & 54.6 & 52.6 & \\
\hline \multirow{2}{*}{$\begin{array}{l}\text { Forward and reverse primers targeting 16s rRNA (BB28_ } \\
\text { RS07070) }\end{array}$} & Myco_16S_F1 & CCGGATAGGACCACACACTT & 56.6 & 55 & 91 \\
\hline & Myco_16S_R1 & ATTACCCCACCAACAAGCTG & 55.4 & 50 & \\
\hline
\end{tabular}

the attachment junctions attL and $a t t R$, indicating the presence of the prophage (Table 3). The attB PCR product was sequenced to confirm the clean excision of the prophage.

\section{Isolation of lysogenic strains}

Lysogens were isolated by plating serially diluted $M$. chelonae strains in $4.5 \mathrm{ml}$ of $7 \mathrm{H} 9$ top agar onto $7 \mathrm{H} 10$ agar treated or not treated with $10^{9}$ PFUs of BPs. After $6 \mathrm{~d}$ of incubation at $30{ }^{\circ} \mathrm{C}$, colonies were picked and screened for properties indicative of lysogens, including release of phage particles into culture supernatant, superinfection immunity to BPs infection and PCR detection of prophage attachment sites, $a t t \mathrm{~L}$ and $a t t \mathrm{R}$ (Table 3 ). The efficiency of lysogeny was determined by dividing the number of colonies present on virus-treated plates by the number of colonies present on un-treated plates and multiplying by 100 . Genomic DNA from BPs lysogens of the WT $M$. chelonae strain (referred to as $M$. chelonae double lysogen (BPs, McProf)) (Table 2) were sequenced to confirm the presence of the BPs genome in the $M$. chelonae genome. Whole genome libraries were generated by Genome Technologies at Jackson Laboratory (Bar Harbor, ME) and sequenced on one 2X150-bp MiSeq sequence run. Sequence reads were assembled by aligning reads to a reference genome and reads that did not map to the host genome were assembled de novo.

\section{RNA isolations}

Total RNA was isolated from six replicates of 4-ml samples of $M$. chelonae grown to an $\mathrm{OD}_{600}$ of 1.0. Cultures were treated with RNAProtect Bacteria Reagent (Qiagen, Germantown, MD) before centrifuging at $5000 \times \mathrm{x}$ for $10 \mathrm{~min}$. Cell pellets were resuspended in $100 \mu \mathrm{l}$ of TE containing $100 \mu \mathrm{g} \mathrm{ml}^{-1}$ lysozyme and incubated at room temperature for $40 \mathrm{~min}$. After adding $700 \mu \mathrm{l}$ of RLT buffer (Qiagen), cells were transferred to 2-ml Lysing Matrix B tubes (MP Biomedicals, Irvine, CA) and homogenized in ice-cold adaptors in the TissueLyser LT (Qiagen) set for $8 \mathrm{~min}$ at $50 \mathrm{~Hz}$. RNA extractions were carried out on the lysates using the RNeasy Mini Kit (Qiagen) with DNAse treatment (Qiagen) on the column according to the manufacturer's recommendations. After elution of RNA in $50 \mu \mathrm{l}$ of water, samples were treated with a second application of DNAse using the Turbo DNA-free Kit (Thermo Scientific, Waltham, MA) according to the manufacturer's recommendations. The quantity of RNA was determined with the NanoDrop ND-1000 spectrophotometer (NanoDrop Technologies, Montchanin, DE, USA). The quality of RNA was determined by gel electrophoresis using the FlashGel RNA system (Lonza, Rockland, ME).

In the $\mathrm{ACI}$ and $\mathrm{AMK}$ induction experiments, RNA was isolated as described above with the following modifications. Cultures were grown to an $\mathrm{OD}_{600}$ of 0.7 or 0.9 and treated with $75 \mu \mathrm{M}$ ACI for $3 \mathrm{~h}$ or with $16.7 \mu \mathrm{M}$ AMK for $1 \mathrm{~h}$, respectively, before harvesting cells for RNA. Untreated control cultures were incubated for equivalent amount of time prior to harvesting cells.

\section{RNAseq}

RNA used in RNAseq experiments was sent to the Delaware DNA Sequencing and Genotyping Center (Newark, DE) for quality control analysis, library preparation and paired end sequencing on the Illumina HiSeq 2500. Read length was set to 51 bases with the samples run on two separate lanes. Raw sequencing data files were uploaded to the public Galaxy server at usegalaxy.org [56]. Read files from the two lanes were concatenated and read quality was determined using FastQC [57]. The reads were processed using the Trim Galore! with the FastQC output as a guide [58]. Retained reads had a quality score minimum of 30, and with the first 9 bases on the 5' end and the last base on the 3' end removed. Though rRNA was depleted prior to sequencing, we discovered that depletion of $r R N A$ was incomplete. The $r R N A$ reads were computationally removed by alignment to the $M$. chelonae rRNA operon using BowTie2 and saving the non-aligned reads [59]. Average number of reads per sample was 2,280,954 reads for the $M$. chelonae (McProf) samples and 2,484,260 reads for the double lysogen (BPs, McProf) samples This gave us an average read depth of 40 reads per base for the transcriptome of both the WT (McProf) and double (BPs, McProf) lysogen samples. Processed reads were then quantitated using Salmon [60] by aligning in a strand-specific 
orientation to the M. chelonae (CCUG 47445) transcriptome using a coding transcript fasta (GenBank). The alignment was adjusted for the high GC content of the mycobacterial genome. Mate pair 1 was specified as coming from the reverse strand (SR). Strand specificity was necessary because reads from two convergent genes often overlapped.

Output from Salmon quantification was used for pairwise comparisons of expression, using the $R$ statistical package DESeq2 [61] and the NumReads values as described by the authors. Genes with low expression levels (reads $<10)$ were removed. Genes were considered significantly regulated if Log 2 fold change $(\log 2 F C)$ was greater than 1.0 and the False Discovery Rate (FDR) was less than 0.05. Although the $M$. chelonae genome is sequenced and has an annotation, the gene functions are poorly characterized. We therefore generated a table of $M$. chelonae genes with orthologs in M. tuberculosis, $M$. abscessus and M. smegmatis using the OrthoDB pipeline, a series of scripts from OrthoDB [62]. This gave us the best alignment between the three genomes and together with blastP on MycoBrowser and HHpred, helped identify numerous significantly upregulated $M$. chelonae genes with potential virulence functions [62-64]. The RNAseq data set was validated in two independent RNA isolation experiments using $\mathrm{qPCR}$ assays that quantified expression of upregulated (whiB7 and tap) and downregulated genes (glycerol kinase $(g l p \mathrm{~K})$ ) from the RNAseq data set (data not shown).

\section{RTqPCR}

cDNA was synthesized from 500 ng of total RNA in 20$\mu \mathrm{l}$ reactions containing qScript cDNA Supermix (Quantabio, Beverly, MA) according to the manufacturer's recommendations. Reactions were incubated for $5 \mathrm{~min}$ at $25^{\circ} \mathrm{C}, 20 \mathrm{~min}$ at $42^{\circ} \mathrm{C}$ and heat inactivated at $85^{\circ} \mathrm{C}$ for 5 min. cDNA was diluted 1:6 in $10 \mathrm{mM}$ Tris and stored at $-20^{\circ} \mathrm{C}$

Real-time PCR assays were performed using the BioRad CFX96 Real-Time system (Bio-Rad Laboratories, Hercules, CA). Using Primer3 software, primer sets were designed to amplify a 100-bp sequence in the gene of interest (Table 6). Quantitative PCR (qPCR) was carried out in triplicate $25-\mu \mathrm{L}$ reactions containing $200 \mathrm{nM}$ gene-specific primers (Table 6), $1 \mu \mathrm{l}$ diluted cDNA (1:5) and PerfeCTa SYBR Green Supermix (Quantabio), according to manufacturer's instructions. Reactions were incubated at $95^{\circ} \mathrm{C}$ for $3 \mathrm{~min}$, followed by 40 cycles of $95^{\circ} \mathrm{C}$ for $10 \mathrm{~s}$ and $60^{\circ} \mathrm{C}$ for $30 \mathrm{~s}$. A melt curve analysis was performed to confirm that only one amplicon was created by each primer set. The change in abundance of gene-specific RNA was normalized to $M$. chelonae $16 \mathrm{~s}$ $r R N A$ and calculated using the $2^{-\Delta \Delta C T}$ method [65].
Positive and no-template controls were included in realtime PCR analysis.

\section{Minimum inhibitory concentration determination}

Minimum inhibitory concentration (MIC) assays were performed according to Burian et al. (2012) and Ramon-Garcia et al. (2013) [14, 66]. Briefly, cultures were grown for $2 \mathrm{~d}$ in $7 \mathrm{H} 9$ supplemented with $\mathrm{OAD}$ and then sub-cultured such that overnight incubation at $30{ }^{\circ} \mathrm{C}$ with shaking allowed cultures to reach an $\mathrm{OD}_{600}$ of $0.1-0.3$. Cultures were diluted to a density of $10^{5}$ cells $\mathrm{ml}^{-1}$ and applied in $50-\mu \mathrm{l}$ volumes to wells of a 96-well plate containing $50 \mu \mathrm{l}$ of $7 \mathrm{H} 9$ media with antibiotic concentrations that varied by 2 -fold dilutions across the plate. Because clarithromycin was prepared in DMSO, an equivalent amount of DMSO was included in all wells. Each strain was tested at each antibiotic concentration in replicates of six and no-antibiotic controls were performed in replicates of 16. Inoculated plates were sealed with porous adhesive culture plate films (VWR International, Radnor, PA), wrapped with parafilm and incubated at $30{ }^{\circ} \mathrm{C}$ for two $\mathrm{d}$ before adding $1 \mu \mathrm{l}$ (assays presented in Figs. 1 and 2) or $2 \mu \mathrm{l}$ (assays presented in Fig. 3) of AlamarBlue (BioRad, Hercules, CA) and $25 \mu \mathrm{l}$ of $25 \%$ Tween 80 to each well. After incubation at $30^{\circ} \mathrm{C}$ for 1 $\mathrm{d}$, the MIC was determined as the lowest drug concentration that completely inhibited growth. Viability was also determined by measuring the optical density at 570 - and $600 \mathrm{~nm}$ and the percent viability of cells was calculated as the percent difference in reduction between antibiotic-treated cells and untreated cells according to the manufacturer's instructions. Each assay was replicated in at least three independent experiments.

\section{McProf genome analysis}

The McProf genome was detected in the $M$. chelonae genome using Phaster [67]. The genome ends were defined as attL and $a t t R$ and the sequence was annotated using DNA Master (http://cobamide2.bio.pitt.edu) and PECAAN (https://pecaan.kbrinsgd.org/index.html). Genes were identified and gene start coordinates determined first by auto-annotation using Glimmer and GeneMark, then by manual inspection of each predicted gene $[68,69]$. Gene functions were predicted using HHPRED and BLAST [70, 71]. Genome map representations were created in Phamerator using database McProf_DB [34].

\section{Acknowledgements}

We would like to thank Dr. Graham Hatfull for providing Mycobacterium phage BPs and for his advice and suggestions in the preparation of this manuscript. We thank Erica Sewall for the discovery of McProf. We also thank Dr. Brewster Kingham and the University of Delaware DNA Sequencing and 
Genotyping Center for assistance with RNAseq sequencing services. We thank Dr. Heidi Munger at Genome Technologies of The Jackson Laboratory (Bar Harbor, ME) for assistance and services sequencing bacterial genomes and Dr. Benjamin King of the University of Maine for his assistance with bioinformatic analyses.

\section{Authors' contributions}

Study conception and design: JC, KWH and SDM; data acquisition, analysis and interpretation: JC, EF, SM, AS, KWH and SDM; manuscript writing: JC, $\mathrm{KWH}$ and SDM. All authors read and approved the final manuscript.

\section{Funding}

Research reported in this project was supported by a University of Maine Faculty Development Grant and by an Institutional Development Award (IDeA) from the National Institute of General Medical Sciences of the National Institutes of Health under grant number P20GM103423.

\section{Availability of data and materials}

The RNAseq data set analyzed during this study is deposited in the Gene expression Omnibus (GEO) with the accession number GSE164210, https:// www.ncbi.n/m.nih.gov/geo/query/acc.cgi?\&acc=GSE164210.

\section{Declarations}

Ethics approval and consent to participate

Not applicable.

\section{Consent for publication}

Not applicable.

\section{Competing interests}

The authors declare that they have no competing interests.

Received: 9 January 2021 Accepted: 5 May 2021

Published online: 09 June 2021

\section{References}

1. Wang X, Kim Y, Ma Q, Hong SH, Pokusaeva K, Sturino JM, et al. Cryptic prophages help bacteria cope with adverse environments. Nat Commun. 2010;1(1):1-9.

2. Wang X, Wood TK. Cryptic prophages as targets for drug development. Drug Resist Updat. 2016;27:30-8. https://doi.org/10.1016/j.drup.2016.06.001

3. Fan X, Xie L, Li W, Xie J. Prophage-like elements present in Mycobacterium genomes. BMC Genomics. 2014;15(1):243. https://doi.org/10.1186/1471-21 64-15-243.

4. Glickman C, Kammlade SM, Hasan NA, Epperson LE, Davidson RM, Strong M. Characterization of integrated prophages within diverse species of clinical nontuberculous mycobacteria. Virol J. 2020;17(1):1-13.

5. Griffith DE. Mycobacterium abscessus and antibiotic resistance: same as it ever was. Clin Infect Dis. 2019;69(10):1687-9. https://doi.org/10.1093/cid/ ciz071.

6. Johansen MD, Herrmann J-L, Kremer L. Non-tuberculous mycobacteria and the rise of Mycobacterium abscessus. Nat Rev Microbiol. 2020:1-16.

7. Guo Q, Chen J, Zhang S, Zou Y, Zhang Y, Huang D, et al. Efflux pumps contribute to intrinsic clarithromycin resistance in clinical, Mycobacterium abscessus Isolates. InfectDrug Resist. 2020;13:447-54. https://doi.org/10.214 7/IDR.S239850

8. Burian J, Thompson CJ. Regulatory genes coordinating antibiotic-induced changes in promoter activity and early transcriptional termination of the mycobacterial intrinsic resistance gene whiB7. Mol Microbiol. 2018;107(3): 402-15. https://doi.org/10.1111/mmi.13890.

9. Nessar R, Cambau E, Reyrat JM, Murray A, Gicquel B. Mycobacterium abscessus: a new antibiotic nightmare. J Antimicrob Chemother. 2012;67(4): 810-8. https://doi.org/10.1093/jac/dkr578.

10. Burian J, Ramon-Garcia S, Howes CG, Thompson CJ. WhiB7, a transcriptional activator that coordinates physiology with intrinsic drug resistance in Mycobacterium tuberculosis. Expert Rev Anti-Infect Ther. 2012;10(9):1037-47. https://doi.org/10.1586/eri.12.90.

11. Burian J, Yim G, Hsing M, Axerio-Cilies P, Cherkasov A, Spiegelman GB, et al. The mycobacterial antibiotic resistance determinant WhiB7 acts as a transcriptional activator by binding the primary sigma factor SigA (RpoV). Nucleic Acids Res. 2013:41(22):10062-76. https://doi.org/10.1093/nar/gkt751.

12. Hurst-Hess K, Rudra P, Ghosh P: Mycobacterium abscessus WhiB7 Regulates a Species-Specific Repertoire of Genes To Confer Extreme Antibiotic Resistance. Antimicrob Agents Chemother. 2017;61(11):e01347-17.

13. Wu M, Li B, Guo Q, Xu L, Zou Y, Zhang Y, et al. Detection and molecular characterisation of amikacin-resistant Mycobacterium abscessus isolated from patients with pulmonary disease. J Global Antimicrobial Resist. 2019;19: 188-91. https://doi.org/10.1016/j.jgar.2019.05.016.

14. Burian J, Ramon-Garcia S, Sweet G, Gomez-Velasco A, Av-Gay Y, Thompson CJ. The mycobacterial transcriptional regulator whiB7 gene links redox homeostasis and intrinsic antibiotic resistance. J Biol Chem. 2012;287(1):299_ 310. https://doi.org/10.1074/jbc.M111.302588.

15. Morris RP, Nguyen L, Gatfield J, Visconti K, Nguyen K, Schnappinger D, et al. Ancestral antibiotic resistance in $<$ em $>$ Mycobacterium tuberculosis $</$ em $>$. Proc Natl Acad Sci U S A. 2005;102(34):12200-5. https://doi.org/10.1073/pna s.0505446102.

16. Dheda K, Lenders L, Magombedze G, Srivastava S, Raj P, Arning E, et al. Drug-penetration gradients associated with acquired drug resistance in patients with tuberculosis. Am J Respir Crit Care Med. 2018;198(9):1208-19. https://doi.org/10.1164/rccm.201711-23330C.

17. Organization WH: Global tuberculosis report 2019. Geneva: World Health Organization; 2019. In.; 2019

18. Brüssow H, Canchaya C, Hardt W-D. Phages and the evolution of bacterial pathogens: from genomic rearrangements to lysogenic conversion. Microbiol Mol Biol Rev. 2004;68(3):560-602. https://doi.org/10.1128/MMBR. 68.3.560-602.2004

19. Figueroa-Bossi N, Uzzau S, Maloriol D, Bossi L. Variable assortment of prophages provides a transferable repertoire of pathogenic determinants in salmonella. Mol Microbiol. 2001;39(2):260-72. https://doi.org/10.1046/j.13 65-2958.2001.02234.x

20. Christensen SK, Mikkelsen M, Pedersen K, Gerdes K. RelE, a global inhibitor of translation, is activated during nutritional stress. Proc Natl Acad Sci. 2001; 98(25):14328-33. https://doi.org/10.1073/pnas.251327898.

21. Guo Y, Quiroga C, Chen Q, McAnulty MJ, Benedik MJ, Wood TK, et al. RalR (a DNase) and RalA (a small RNA) form a type I toxin-antitoxin system in Escherichia coli. Nucleic Acids Res. 2014;42(10):6448-62. https://doi.org/10.1 093/nar/gku279.

22. Neubauer C, Gao Y-G, Andersen KR, Dunham CM, Kelley AC, Hentschel J, et al. The structural basis for mRNA recognition and cleavage by the ribosome-dependent endonuclease RelE. Cell. 2009;139(6):1084-95. https:// doi.org/10.1016/j.cell.2009.11.015.

23. Bibb LA, Hatfull GF. Integration and excision of the Mycobacterium tuberculosis prophage-like element, $\varphi$ Rv1. Mol Microbiol. 2002;45(6):151526. https://doi.org/10.1046/j.1365-2958.2002.03130.x

24. Fan X, Abd Alla AAE, Xie J. Distribution and function of prophage phiRv1 and phiRv2 among Mycobacterium tuberculosis complex. J Biomol Struct Dyn. 2016;34(2):233-8. https://doi.org/10.1080/07391102.2015.1022602.

25. van Ingen J, de Zwaan R, Dekhuiizen RP, Boeree MJ, van Soolingen D. Clinical relevance of Mycobacterium chelonae-abscessus group isolation in 95 patients. J Infect. 2009;59(5):324-31. https://doi.org/10.1016/j.jinf.2009.08. 016.

26. Hatfull GF. Complete genome sequences of 63 mycobacteriophages Genome Announcements 2013;1(6):e00847-13.

27. Hatfull GF, Jacobs-Sera D, Lawrence JG, Pope WH, Russell DA, Ko C-C, et al. Comparative genomic analysis of 60 mycobacteriophage genomes: genome clustering, gene acquisition, and gene size. J Mol Biol. 2010;397(1): 119-43. https://doi.org/10.1016/j.jmb.2010.01.011.

28. Sampson T, Broussard GW, Marinelli LJ, Jacobs-Sera D, Ray M, Ko CC, et al. Mycobacteriophages BPs, angel and halo: comparative genomics reveals a novel class of ultra-small mobile genetic elements. Microbiol. 2009;155(Pt 9): 2962-77. https://doi.org/10.1099/mic.0.030486-0.

29. Broussard GW, Oldfield LM, Villanueva VM, Lunt BL, Shine EE, Hatfull GF. Integration-dependent bacteriophage immunity provides insights into the evolution of genetic switches. Mol Cell. 2013;49(2):237-48. https://doi.org/1 0.1016/j.molcel.2012.11.012

30. Parikh A, Kumar D, Chawla Y, Kurthkoti K, Khan S, Varshney U, et al. Development of a new generation of vectors for gene expression, gene replacement, and protein-protein interaction studies in mycobacteria. Appl Environ Microbiol. 2013:79(5):1718-29. https://doi.org/10.1128/AEM.03 695-12. 
31. Nash KA, Brown-Elliott BA, Wallace RJ. A novel gene, erm (41), confers inducible macrolide resistance to clinical isolates of Mycobacterium abscessus but is absent from Mycobacterium chelonae. Antimicrob Agents Chemother. 2009;53(4):1367-76. https://doi.org/10.1128/AAC.01275-08.

32. Rudra P, Hurst-Hess KR, Cotten KL, Partida-Miranda A, Ghosh P. Mycobacterial HflX is a ribosome splitting factor that mediates antibiotic resistance. Proc Natl Acad Sci. 2020;117(1):629-34. https://doi.org/10.1073/ pnas.1906748117.

33. Ehrt S, Guo XV, Hickey CM, Ryou M, Monteleone M, Riley LW, et al. Controlling gene expression in mycobacteria with anhydrotetracycline and Tet repressor. Nucleic Acids Res. 2005;33(2):e21. https://doi.org/10.1093/nar/gni013.

34. Cresawn SG, Bogel M, Day N, Jacobs-Sera D, Hendrix RW, Hatfull GF. Phamerator: a bioinformatic tool for comparative bacteriophage genomics. BMC Bioinformatics. 2011;12(1):395. https://doi.org/10.1186/1471-2105-12-395

35. Russell DA, Hatfull GF. PhagesDB: the actinobacteriophage database. Bioinformatics. 2016;33(5):784-6.

36. Dedrick RM, Jacobs-Sera D, Bustamante CAG, Garlena RA, Mavrich TN, Pope $\mathrm{WH}$, et al. Prophage-mediated defence against viral attack and viral counterdefence. Nat Microbiol. 2017;2(3):16251. https://doi.org/10.1038/nmicrobiol.2 016.251.

37. Pallen MJ. The ESAT-6/WXG100 superfamily-and a new gram-positive secretion system? Trends Microbiol. 2002;10(5):209-12. https://doi.org/10.101 6/S0966-842X(02)02345-4.

38. Daleke MH, Ummels R, Bawono P, Heringa J, Vandenbroucke-Grauls CM, Luirink J, et al. General secretion signal for the mycobacterial type VII secretion pathway. Proc Natl Acad Sci. 2012;109(28):11342-7. https://doi. org/10.1073/pnas.1119453109.

39. Ma L-S, Hachani A, Lin J-S, Filloux A, Lai E-M. Agrobacterium tumefaciens deploys a superfamily of type VI secretion DNase effectors as weapons for interbacterial competition in planta. Cell Host Microbe. 2014;16(1):94-104. https://doi.org/10.1016/j.chom.2014.06.002.

40. Ratnatunga CN, Lutzky VP, Kupz A, Doolan DL, Reid DW, Field M, et al. The rise of non-tuberculosis mycobacterial lung disease. Front Immunol. 2020; 11:303. https://doi.org/10.3389/fimmu.2020.00303.

41. Pryjma M, Burian J, Kuchinski K, Thompson CJ. Antagonism between FrontLine Antibiotics Clarithromycin and Amikacin in the Treatment of Mycobacterium abscessus Infections Is Mediated by the whiB7 Gene. Antimicrob Agents Chemother 2017;61(11):e01353-17.

42. Aínsa JA, Blokpoel MC, Otal I, Young DB, De Smet KA, Martín C. Molecular cloning and characterization of tap, a putative multidrug efflux pump present in Mycobacterium fortuitum and Mycobacterium tuberculosis. J Bacteriol. 1998; 180(22):5836-43. https://doi.org/10.1128/JB.180.22.5836-5843.1998.

43. Chen W, Green KD, Tsodikov OV, Garneau-Tsodikova S. Aminoglycoside multiacetylating activity of the enhanced intracellular survival protein from Mycobacterium smegmatis and its inhibition. Biochemistry. 2012;51(24): 4959-67. https://doi.org/10.1021/bi3004473.

44. Luthra S, Rominski A, Sander P. The role of antibiotic-target-modifying and antibiotic-modifying enzymes in Mycobacterium abscessus drug resistance. Front Microbiol. 2018;9:2179. https://doi.org/10.3389/fmicb.2018.02179.

45. De Rossi E, Arrigo P, Bellinzoni M, Silva PA, Martín C, Aínsa JA, et al. The multidrug transporters belonging to major facilitator superfamily in Mycobacterium tuberculosis. Mol Med. 2002;8(11):714-24. https://doi.org/1 $0.1007 / B F 03402035$.

46. De Rossi E, Blokpoel MC, Cantoni R, Branzoni M, Riccardi G, Young DB, et al. Molecular cloning and functional analysis of a novel tetracycline resistance determinant, tet $(V)$, fromMycobacterium smegmatis. Antimicrob Agents Chemother. 1998;42(8):1931-7. https://doi.org/10.1128/AAC.42.8.1931.

47. Kumar A, Alam A, Bharadwaj P, Tapadar S, Rani M, Hasnain SE. ToxinAntitoxin (TA) Systems in Stress Survival and Pathogenesis. In: Mycobacterium Tuberculosis: Molecular Infection Biology, Pathogenesis, Diagnostics and New Interventions, Springer, Singapore, 2019:257-274.

48. LeRoux M, Kirkpatrick RL, Montauti El, Tran BQ, Peterson SB, Harding BN, et al. Kin cell lysis is a danger signal that activates antibacterial pathways of Pseudomonas aeruginosa. eLife. 2015;4:e05701. https:/doi.org/10.7554/eLife.05701.

49. Slayden RA, Dawson CC, Cummings JE: Toxin-antitoxin systems and regulatory mechanisms in Mycobacterium tuberculosis. Pathogens Dis 2018 76(4):fty039.

50. Wang X, Kim Y, Hong SH, Ma Q, Brown BL, Pu M, et al. Antitoxin MqsA helps mediate the bacterial general stress response. Nat Chem Biol. 2011; 7(6):359-66. https://doi.org/10.1038/nchembio.560.
51. Zhang Y, Xia B, Li M, Shi J, Long Y, Jin Y, et al. HigB reciprocally controls biofilm formation and the expression of type III secretion system genes through influencing the intracellular c-di-GMP level in Pseudomonas aeruginosa. Toxins. 2018;10(11):424. https://doi.org/10.3390/toxins10110424.

52. Fraikin N, Goormaghtigh F, Van Melderen L. Type II toxin-antitoxin systems: evolution and revolutions. J Bacteriol. 2020;202(7):e00763-19.

53. Wozniak RA, Waldor MK. A toxin-antitoxin system promotes the maintenance of an integrative conjugative element. PLoS Genet. 2009;5(3):e1000439.

54. Snapper S, Melton R, Mustafa S, Kieser T, Jr WJ: Isolation and characterization of efficient plasmid transformation mutants of Mycobacterium smegmatis. Mol Microbiol 1990, 4(11):1911-1919, DOl: https://doi.org/10.1111/j.1365-2958.1990.tb02040.x

55. van Kessel JC, Hatfull GF. Recombineering in Mycobacterium tuberculosis. Nat Methods. 2007;4(2):147-52. https://doi.org/10.1038/nmeth996.

56. Afgan E, Baker D, Batut B, Van Den Beek M, Bouvier D, Čech M, et al. The galaxy platform for accessible, reproducible and collaborative biomedical analyses: 2018 update. Nucleic Acids Res. 2018;46(W1):W537-44. https://doi. org/10.1093/nar/gky379.

57. Andrew S. FastQC: a quality control tool for high throughput sequence data. Available online at: http://www.bioinformatics.babraham.ac.uk/ projects/fastqc.

58. Kreuger F: Trim Galore! v0.6.3 http://www.bioinformatics.babraham.ac.uk/ projects/trim_galore/. In.; 2019.

59. Langmead B, Salzberg SL. Fast gapped-read alignment with bowtie 2. Nat Methods. 2012;9(4):357-9. https://doi.org/10.1038/nmeth.1923.

60. Patro R, Duggal G, Love MI, Irizarry RA, Kingsford C. Salmon provides fast and bias-aware quantification of transcript expression. Nat Methods. 2017; 14(4):417-9. https://doi.org/10.1038/nmeth.4197.

61. Love MI, Huber W, Anders S. Moderated estimation of fold change and dispersion for RNA-seq data with DESeq2. Genome Biol. 2014;15(12):550. https://doi.org/10.1186/s13059-014-0550-8.

62. Zdobnov EM, Tegenfeldt F, Kuznetsov D, Waterhouse RM, Simao FA, loannidis $\mathrm{P}$, et al. OrthoDB v9. 1: cataloging evolutionary and functional annotations for animal, fungal, plant, archaeal, bacterial and viral orthologs. Nucleic Acids Res. 2017:45(D1):D744-9. https://doi.org/10.1093/nar/gkw1119.

63. Kapopoulou A, Lew JM, Cole ST. The MycoBrowser portal: a comprehensive and manually annotated resource for mycobacterial genomes. Tuberculosis. 2011;91(1):8-13. https://doi.org/10.1016/j.tube.2010.09.006.

64. Zimmermann L, Stephens A, Nam S-Z, Rau D, Kübler J, Lozajic M, et al. A completely reimplemented MPI bioinformatics toolkit with a new HHpred server at its core. J Mol Biol. 2018;430(15):2237-43. https://doi.org/10.1016/j. jmb.2017.12.007

65. Livak KJ, Schmittgen TD. Analysis of relative gene expression data using real-time quantitative $P C R$ and the $2-\Delta \Delta C T$ method. Methods. 2001;25(4): 402-8.

66. Ramón-García S, Ng C, Jensen PR, Dosanjh M, Burian J, Morris RP, et al. WhiB7, an Fe-S-dependent transcription factor that activates species-specific repertoires of drug resistance determinants in actinobacteria. J Biol Chem. 2013;288(48):34514-28. https://doi.org/10.1074/jbc.M113.516385.

67. Arndt D, Grant JR, Marcu A, Sajed T, Pon A, Liang Y, et al. PHASTER: a better, faster version of the PHAST phage search tool. Nucleic Acids Res. 2016; 44(W1):W16-21. https://doi.org/10.1093/nar/gkw387.

68. Borodovsky M, Mills R, Besemer J, Lomsadze A. Prokaryotic gene prediction using GeneMark and GeneMark. hmm. Curr Protocols Bioinformatics 2003; 1(1):4.5. 1-4.5. 16

69. Delcher AL, Harmon D, Kasif S, White O, Salzberg SL. Improved microbial gene identification with GLIMMER. Nucleic Acids Res. 1999;27(23):4636-41. https://doi.org/10.1093/nar/27.23.4636.

70. Altschul SF, Gish W, Miller W, Myers EW, Lipman DJ. Basic local alignment search tool. J Mol Biol. 1990;215(3):403-10. https://doi.org/10.1016/S0022-2 836(05)80360-2.

71. Söding J, Biegert A, Lupas AN. The HHpred interactive server for protein homology detection and structure prediction. Nucleic Acids Res. 2005; 33(suppl_2):W244-W248.

\section{Publisher's Note}

Springer Nature remains neutral with regard to jurisdictional claims in published maps and institutional affiliations. 